IZA DP No. 9365

Are Public or Private Providers of Employment

Services More Effective?

Evidence from a Randomized Experiment

Kai Rehwald

Michael Rosholm

Michael Svarer

September 2015 


\title{
Are Public or Private Providers of Employment Services More Effective? Evidence from a Randomized Experiment
}

\author{
Kai Rehwald \\ Aarhus University \\ Michael Rosholm \\ Aarhus University \\ and IZA \\ Michael Svarer \\ Aarhus University \\ and IZA \\ Discussion Paper No. 9365 \\ September 2015 \\ IZA \\ P.O. Box 7240 \\ 53072 Bonn \\ Germany \\ Phone: $+49-228-3894-0$ \\ Fax: +49-228-3894-180 \\ E-mail: iza@iza.org
}

\begin{abstract}
Any opinions expressed here are those of the author(s) and not those of IZA. Research published in this series may include views on policy, but the institute itself takes no institutional policy positions. The IZA research network is committed to the IZA Guiding Principles of Research Integrity.

The Institute for the Study of Labor (IZA) in Bonn is a local and virtual international research center and a place of communication between science, politics and business. IZA is an independent nonprofit organization supported by Deutsche Post Foundation. The center is associated with the University of Bonn and offers a stimulating research environment through its international network, workshops and conferences, data service, project support, research visits and doctoral program. IZA engages in (i) original and internationally competitive research in all fields of labor economics, (ii) development of policy concepts, and (iii) dissemination of research results and concepts to the interested public.
\end{abstract}

IZA Discussion Papers often represent preliminary work and are circulated to encourage discussion. Citation of such a paper should account for its provisional character. A revised version may be available directly from the author. 
IZA Discussion Paper No. 9365

September 2015

\section{ABSTRACT}

\section{Are Public or Private Providers of Employment Services More Effective? Evidence from a Randomized Experiment}

This paper compares the effectiveness of public and private providers of employment services. Reporting from a randomized field experiment conducted in Denmark we assess empirically the case for contracting out employment services for a well-defined group of highly educated job-seekers (unemployed holding a university degree). Our findings suggest, first, that private providers deliver more intense, employment-oriented, and earlier services. Second, public and private provision of employment services are equally effective regarding subsequent labour market outcomes. And third, the two competing service delivery systems appear to be equally costly from a public spending perspective.

JEL Classification: J64, J68, H41, H43, H44, L33

Keywords: active labour market policies, job-search assistance, contracting out, private provision of employment services, treatment effect evaluation, randomized trial, cost-analysis

Corresponding author:

Michael Svarer

Department of Economics and Business

Aarhus University

Fuglesangs Allé 4

DK - 8210 Aarhus V

Denmark

E-mail: msvarer@econ.au.dk 


\section{Introduction}

"What to produce, how to produce, and for whom to produce", so the phrase goes, are the three fundamental questions of economics. In the context of active labour market policies (ALMPs) one might ask: What is the optimal policy mix, how can it best be implemented, and who is the target group? While the answer to the last question is obvious enough ("the unemployed"), and while some progress has been made towards answering the first (see Card, Kluve, and Weber (2010) for a meta-analysis of ALMP evaluation studies), the second question has been a blind spot in the literature for decades. ${ }^{1}$ How can ALMPs best be implemented, and, for that matter, how shall service delivery best be organized? An important aspect in this regard is the choice of a suitable service provider. The paper at hand analyzes whether public or private provision of employment services is more effective.

Traditionally, employment services are publicly provided services delivered by municipal job centers. Heckman, LaLonde, and Smith (1999: 1867) refer to public provision of employment and training programs as "a feature of the modern welfare state". Recently however, it has become an international trend to contract out formerly publicly provided services to other actors, above all private enterprises - see Finn (2011) for an overview of recent trends in Europe. From a theoretical perspective, it is unclear whether public or private provision of employment services is more effective. Efficiency gains induced by market competition may be offset by transaction costs arising for setting-up, running, and regulating a quasi-market for employment services and by adverse impacts of hard-to-solve agency problems. Is the market able to deliver on its promises or should preference be given to in-house service provision by state-run agencies? Since economic theory alone does not provide an answer, we will approach the research question empirically.

In particular, we are reporting from a randomized trial conducted in Denmark. The target group consists of newly registered unemployed individuals with long-cycle higher education (university graduates), who were randomly assigned to receive either governmentally-supplied public or contracted-out private employment services. The trial resembles previous experiments conducted in the US, Germany, Sweden, and France (Carcagno, Cecil, and Ohls, 1982; Krug and Stephan, 2013; Bennmarker, Grönqvist, and Öckert, 2013; Laun and Thoursie, 2014; Behaghel, Crépon, and Gurgand, 2014). Notwithstanding, the focus on highly educated job-seekers is unprecedented in this context; all previous studies focus on economically disadvantaged populations, primarily on hard-to-place and other at-risk of long-term unemployment individuals. By analyzing whether public or private provision of employment services is more effective for the highly educated, we fill an important research gap: since unemployed holding a university degree arguably face a wholly different labour market than the typical unemployed, earlier trials tell

\footnotetext{
${ }^{1}$ The study by Zweifel and Zaborowski (1996) being a notable exception.
} 
us very little about the likely effects of contracting out employment services for this particular group. Public job centers may lack the resources for and the expertise in dealing with highly specialized labour and the associated recruitment process of private sector firms. Private providers could fill this market niche by means of specialization and their natural proximity to the private sector. On the other hand, however, many highly educated individuals strive for public sector jobs, and there, public job centers might have a comparative advantage.

A second distinguishing feature of the present paper is that we consider the contracting-out of the complete array of employment services (counseling, training, and placement), whereas only certain tasks were contracted out in earlier trials. A third major difference is data quality: we are able to link the experiment-specific administrative dataset with high-quality Danish register data. This allows us to track the labour market behaviour of trial participants week by week up to 15 months after random assignment. Moreover, by using high-quality register data we avoid some of the pitfalls of survey data, such as sample attrition caused by item nonresponse, recall bias, and misreporting. And fourthly, in an attempt to compare the per capita "price tags" of both programs, we complement our study by a thorough cost-analysis. Our cost-analysis quantifies the budgetary burdens (net expenditures) associated with public and private service provision and goes somewhat beyond the back-of-the-envelope type cost-evaluations implemented for earlier contracting out trials.

Our findings suggest that - overall - public and private provision of employment services are equally effective regarding subsequent labour market outcomes (regular employment, employment with wage subsidies, non-benefit receipt, unemployment), although there are some indications that being assigned to a private provider tends to be beneficial for men and for individuals with prior employment experience. But none of these effects is statistically significant at conventional levels. Furthermore, the two competing service delivery systems appear to be equally costly from a public spending perspective (net expenses). Regarding working methods, private providers have a higher meeting frequency than public job centers and they deliver more intense, employment-oriented, and earlier services. On the other hand, however, client satisfaction is slightly better in the public track.

\section{Literature}

This chapter reviews the existing literature on the effectiveness of contracting out employment services to private providers. We identified five pertinent randomized evaluations for the cases of the US, Germany, Sweden, and France, as well as four related observational studies. 
Observational Studies Winterhager (2006) analyzes administrative micro-data from Germany, where a quasi-market model for placement services was established in 2002/2003 and where unemployed receiving privately provided services appear to be a positively selected group. The author finds that private provision of placement services is ineffective: public agencies outperform their private counterparts in successfully reintegrating their clients. Only certain subgroups in West Germany benefit from private (instead of public) provision: women, five to nine months after assignment, and older job-seekers, after nine months. A later study by Bernhard and Wolff (2008) focuses on means-tested benefit recipients. Bernhard and Wolff (2008: 4) conclude that "assignment to private providers is generally ineffective (...) regarding the goal of avoiding unemployment and benefit receipt". A third observational study relying on a matching strategy is the one by Skipper and Sørensen (2013) for Denmark, who compare employment rates of unemployed referred to other actors (mostly private firms) with those of a matched control group. Unemployed university graduates - the target group of the present paper - are not part of their study sample in that this particular group was subject to a distinct institutional framework (see Chapter 3). Skipper and Sørensen (2013) find that contracting out placement services has a negative impact on employment rates during the first six months after assignment, by which time they have converged. However, other actors are cheaper than municipal job centers. Still, a supplementary cost-benefit analysis shows that the cost saving cannot compensate for the economic losses associated with lower short-run placement rates; other actors are not cost-effective. Lastly, a recent study by Cockx and Baert (2015) evaluates the effectiveness of contracting out public employment services for long-term unemployed to private for-profit and private non-profit providers in Belgium. The authors find that private for-profit providers performed best.

The Achilles' heel of the matching approach followed in most of the observational studies reviewed above (Cockx and Baert (2015) rely on the timing-of-events method) is the assumption of unconfoundedness (Rosenbaum and Rubin, 1983): the matching estimates have a causal interpretation provided that, conditional on covariates, clients receiving publicly and privately provided services have the same employment potential. If so, the matched control group provides a valid counterfactual and the matching estimator captures the causal effect of interest. Yet, unobserved confounders - variables affecting both assignment and response - result in spurious effects, which might, in turn, lead to wrong conclusions. Since treatment exposure is independent of potential outcomes in case of random assignment, confoundedness is a non-issue in randomized experiments.

Randomized Evaluations Table A1 (Appendix) presents a systematic review of randomized contracting out trials by synthezising research designs and key results of four recent studies conducted in Sweden, Germany, and France. The table's rightmost column summarizes the 
Danish trial evaluated in this paper. The review is comprehensive in that it covers all randomized studies of contracted-out job search, counseling, and placement services that we are aware of. ${ }^{2}$

Bennmarker et al. (2013) analyze the effects of contracting out placement services for hardto-place job-seekers in Sweden. The findings from this randomized experiment suggest that the private agencies' working methods are characterized by a greater labour intensity and that unemployed serviced by private providers are considerably more satisfied. However, this does not generally translate into improved labour market outcomes in terms of employment rates, earnings, and months worked. Subanalyses by migrant status and age reveal that treatment effects are heterogeneous; regarding wage earnings, for instance, immigrants benefit from private provision of job-search assistance, whereas adolescents are better-off at public agencies. Substantial heterogeneity is also found along the dimension of pre-trial earnings: individuals with relatively high pre-treatment earnings benefit from private provision, whereas low-income earners perform better under the public regime. Bennmarker et al. (2013: 81) conclude that "one size does not fit all". Unfortunately, the study does not compare the costs of private and public service provision.

Krug and Stephan (2013) report from a randomized experiment conducted in Germany. In this trial, hard-to-place job-seekers were randomly assigned either to a public or to a private provider of employment services. The study finds that, in the short-run, public in-house provision of intensive placement services leads to better labour market outcomes than contracted-out private provision. In particular, intensive public services are followed by a stronger reduction in unemployment than intensive private ones. While most of the difference is due to an increase of labour force withdrawals among participants in the public program, one third of the effect can be ascribed to higher re-employment rates. Krug and Stephan (2013: 22) conclude that "public provision of placement services can be as least as effective as contracting-out". The results of a supplementary cost-analysis (fiscal net effects) are in favor of public services too.

Behaghel et al. (2014) analyze the effects of a randomized contracting out experiment conducted in France. The trial targeted job-seekers at risk of long-term unemployment, who were randomly assigned to three experimental groups (public standard track, intensive public/private program). Evaluation results suggest that the intensive public program outperformed the private one. The latter appears to have, for instance, no effect on the number of days of unemployment benefit receipt one year after randomization, whereas the former decreases unemployment by more than two weeks. Behaghel et al. (2014: 169) subsume that "private providers appear to be less efficient, especially in the short run, and much less cost-effective than the public program".

\footnotetext{
${ }^{2}$ The study by Carcagno et al. (1982) is a notable exception. In short, Carcagno et al. (1982) report from the Michigan private employment agencies experiment, showing that the use of private contractors in providing employment services for hard-to-place welfare clients is not cost-effective. This study appears to be the very first of its kind. It does, however, suffer from a couple of limitations. Besides a substantial degree of sample attrition and a considerable imbalance in pre-trial employment rates despite random assignment, the study's main limitation is that it does not allow for a fair comparison of public and private service provision: by design, the treatment group received more intense services than the control group.
} 
Lastly, Laun and Thoursie (2014) examine the effects of vocational rehabilitation for the longterm sick and temporary disabled in Sweden. They evaluate a field experiment that randomly assigned individuals in need of rehabilitation to services delivered either by the public employment service or by private contractors. The results indicate that there are neither significant differences in subsequent labour market outcomes, nor differences in average costs. In sum, this study does not substantiate the case for contracting out (given the lack of efficiency gains), but it also provides no clear-cut case against it (given no differences in performance and costs).

To wrap up, the literature to date suggests that contracting out employment services does not generally lead to the desired efficiency gains. In fact, the empirical evidence from the four contracting out trials reviewed above (see Table A1) indicates that public providers of employment services are as least as successful as their private counterparts (Krug and Stephan, 2013; Bennmarker, Grönqvist, and Öckert, 2013; Laun and Thoursie, 2014) - if not better (Behaghel, Crépon, and Gurgand, 2014). However, it stands to reason that the relative merits of private and public service provision may depend on context. All previous trials focus on individuals with relatively poor baseline employment prospects (such as hard-to-place, long-term sick, and temporary disabled individuals). By analyzing whether public or private provision of employment services is more effective for the highly educated, i.e. for clients with relatively high baseline employment prospects, we aim to fill an important research gap in the remainder of this paper.

\section{Institutional Background and the Randomized Experiment}

Background In Denmark, the responsibility for organizing placement services and labour market programs lies with the municipalities: employment services are typically delivered by about 100 municipal job centers aiming to help the unemployed back to work as fast as possible. To provide their clients with targeted services and tailored solutions, job centers may contract out some of their operations to other actors. Other actors is a broad term covering a wide range of organizations, such as private companies, other municipal divisions, and unemployment insurance funds. They are selected through competitive tendering; the National Labour Market Authority issues nationwide calls for tender on a regular basis (more on this below). ${ }^{3}$ While the municipalities have had the possibility to collaborate with other actors since 1999 (Rigsrevision, 2013), the first public call for tender was launched only in January 2003 after it was as a consequence of a labour market policy reform in 2002 - decided to upscale the use of other actors substantially. Back then, it was the government's intention to create a free market for

\footnotetext{
${ }^{3}$ The National Labour Market Authority is part of and directly reports to the Ministry of Employment. It consists of the central labour market authority in Copenhagen and four employment regions (Zealand, Southern Denmark, Central Denmark, North Denmark). The National Labour Market Authority has the responsibility to implement and to monitor employment policies, and is as such one of the main actors in Denmark's active labour market policy. Following its guiding principle to promote a swift return to work with active instruments, it aims to increase employment, to decrease unemployment, and to reduce welfare dependency.
} 
employment services; a market in which competition for contracts and performance pay would create an impetus for innovation and specialization; a market that could be better and cheaper than the old system (Bredgaard, Larsen, and Møller, 2005).

Of particular importance for what follows is that contracting out was the default treatment for unemployed academics from 2007 to 2011: municipalities were legally required to contract out employment services for this group to other actors. Figure 1 displays, for the years 2007 to 2011, the time series of the number of unemployed with long-cycle higher education enrolled with other actors overlaid by the group-specific unemployment rate. Since employment services for all target group members had to be contracted out, it comes as no surprise that enrolment figures in each employment region track the trend in unemployment closely. Unemployment among individuals with long-cycle higher education saw a sharp increase after the financial crisis hit Denmark in Summer 2008; enrolment rates followed suit. ${ }^{4}$

Figure 1: Evolution of enrolment rates by employment region (left axis) and nationwide group-specific unemployment rate (right axis)

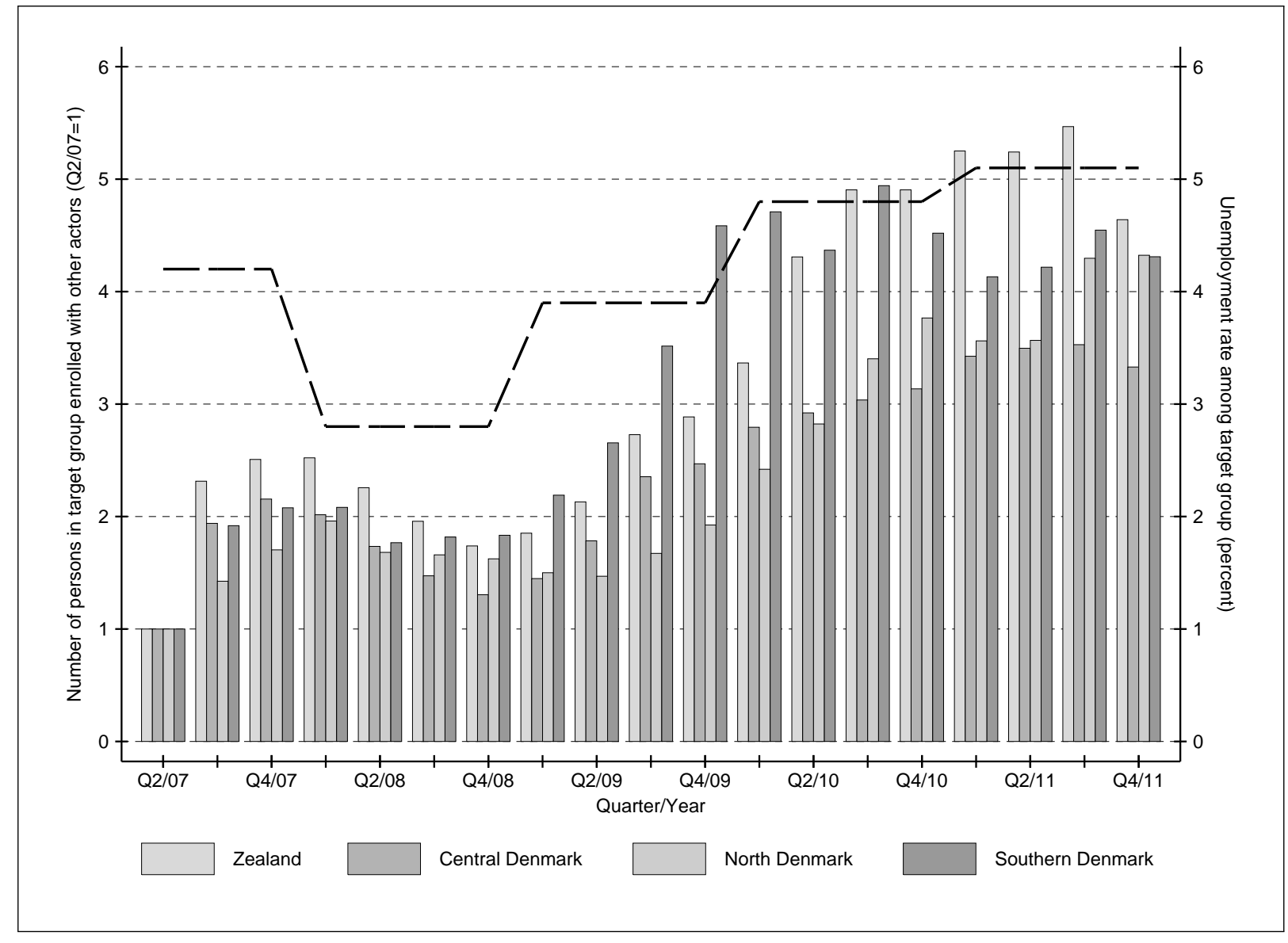

Notes: Data for Q1/07 are not available. Q2/07 is the base year for the time series of enrolment rates (own calculations). Raw data on enrolment rates (shaded bars, left axis) stem from Jobindsats.dk, an online databank administered by the National Labour Market Authority. Data on group-specific unemployment rates (dashed line, right axis) stem from StatBank Denmark, provided by Denmark's national statistics institute.

\footnotetext{
${ }^{4}$ Also note that the figure illustrates the obvious: providing employment services is a countercyclical business, which is small in the boom, but expands in the bust.
} 
The Experiment In early 2011, just shy of half a decade after contracting out became the default treatment for unemployed academics, the initial euphoria for the market-based approach has given way to skepticism as to whether the new quasi-market was indeed better and cheaper than the old system. Given the lack of hard evidence at the time, the National Labour Market Authority launched in late 2011 a randomized trial designed to compare the effectiveness of other actors and public job centers in servicing the target group. The field experiment was conducted in four municipalities all across Denmark, including Denmark's most populous cities Copenhagen and Aarhus. It encompassed all unemployed with long-cycle higher education who would have been referred to an other actor between mid August and mid November 2011 (calender weeks 33 to 46) in the absence of the experimental intervention. This implied that a total of 3,107 experimental units was randomly assigned to treatment (1,541 individuals) and control group (1,566 individuals). While control group members received treatment as usual (referral to an other actor, more on this below), employment services for the treatment group were not contracted out, but instead provided directly by the corresponding job center itself. Notice that all other actors involved in the experiment were private firms, so we use the terms "other actors" and "private providers" interchangeably in the remainder of this paper. Figure A1 in the Appendix depicts the inflow of job-seekers into the experiment by assignment status, target group, regional site, and other actor. Table 1 describes the resulting sample, showing how trial participants are distributed across trial sites, target groups, and calender weeks of intake.

It was initially planned that the experiment lasts 12 months (measured from the individual date of intake), after which both treated and non-treated were supposed to receive treatment as usual, i.e. privately provided services - if any. However, unforeseen changes in the relevant legislation eventually resulted in a slightly different experimental setup. In particular, a law passed November 19th, 2011 repealed the general contracting out requirement for unemployed with long-cycle higher education. For all practical purposes, this meant that all procurement contracts made during the 2010 tendering round (see below) expired by the end of June 2012 and trial participants could not be enrolled with other actors beyond this date. Thus, the experiment came to an early end, and both groups received publicly provided services from July 2012 onwards in case of continued unemployment. Figure 2 illustrates the trial's design. Note that the unanticipated change in the institutional environment does not invalidate our research design in that we still have two groups that differ from each other only in so far that one of them received private services before the end of June 2012, while the other one received public services. As such, differences in labour market outcomes between treated and controls can be ascribed to treatment assignment. 
Table 1: Sample description

\begin{tabular}{lcc}
\hline & Private & Public \\
\hline Panel A: Trial site & & \\
Copenhagen & 71.0 & 71.7 \\
Aarhus & 20.4 & 20.5 \\
Lyngby-Taarbæk & 3.6 & 3.7 \\
Other & 5.0 & 4.1 \\
Panel B: Target group & & \\
Younger than 30 & 46.6 & 43.2 \\
30 or older & 53.5 & 56.9 \\
Panel C: Calender week of intake & \\
CW 33 & 12.3 & 12.3 \\
CW 34 & 7.3 & 7.2 \\
CW 35 & 8.9 & 9.0 \\
CW 36 & 7.3 & 7.3 \\
CW 37 & 9.3 & 9.5 \\
CW 38 & 6.1 & 6.0 \\
CW 39 & 4.5 & 4.5 \\
CW 40 & 7.3 & 7.3 \\
CW 41 & 7.3 & 7.3 \\
CW 42 & 6.3 & 6.4 \\
CW 43 & 5.9 & 5.8 \\
CW 44 & 5.9 & 6.1 \\
CW 45 & 7.2 & 7.1 \\
CW 46 & 4.3 & 4.3 \\
\hline Number of individuals & 1,566 & \\
\hline Notes: The table shows how treated and controls are distributed \\
across trial sites, target groups, and calender weeks of intake. Per- \\
centages in each of the six blocks add up to 100. \\
C.5
\end{tabular}

The 2010 Tendering Round Individuals assigned to control status received treatment as usual, that is to say they were referred to a private provider of employment services after having registered as unemployed with the municipal employment agency. The private providers involved in the experiment have been awarded their service contracts in the 2010 tendering round, which is described in the following.

In 2010, potential contractors were asked to submit offers for providing employment services (counseling and training) for unemployed with long-cycle higher education. Long-cycle higher education is defined as professional education and training of at least five to six years' duration, i.e. usually a master's degree or its equivalent. ${ }^{5}$ Bidders could make offers for servicing one of two target groups (unemployed below/above the age of 30), or both, in one, or several, of Denmark's four employment regions. In particular, bidders had to offer a total price per job-seeker per target group per year. The price was supposed to cover all costs for providing employment services (counseling, training, etc.) during the contract period of 52 weeks. ${ }^{6}$ It consisted of an operation subsidy and a performance based bonus component.

\footnotetext{
${ }^{5}$ Unemployed without relevant work experience in the occupation they have learned (at least six months within the last five years), however, were not covered by the tender, unless they graduated within the last three years.

${ }^{6}$ There are some exceptions to this rule. Wage subsidies, costs for mentors, and expenses for certain auxiliaries (teaching materials, work equipment, office furniture, etc.) were either subsidized (mentor and auxiliaries) or directly paid by the job center (wage subsidies).
} 
Figure 2: Trial design

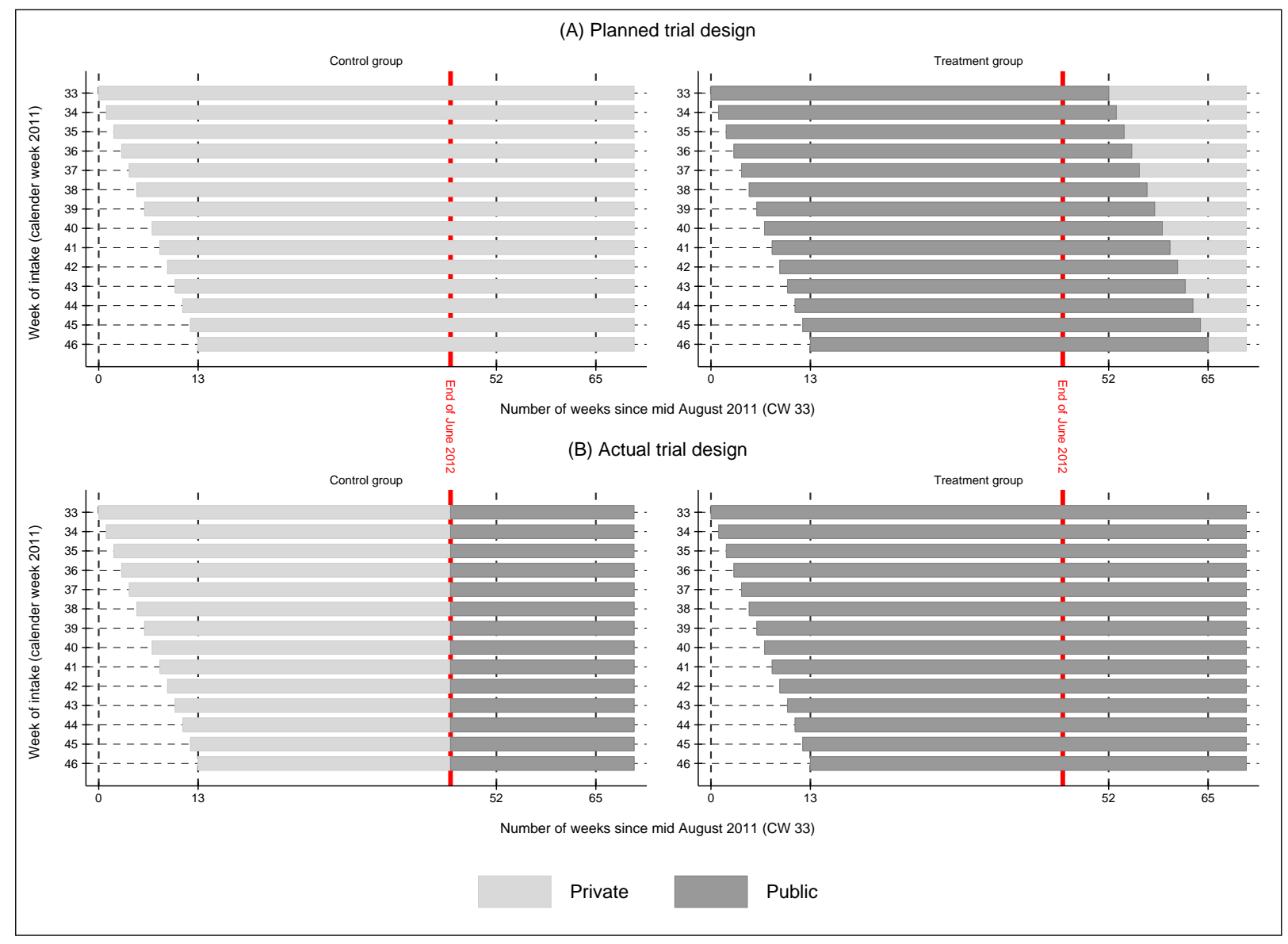

Notes: The figure shows which type of service (private or public) an individual who has - in a given week of intake (calender weeks 33 through 46) - been randomized into a particular group (control group or treatment group) receives in a given week after enrolment as indicated on the horizontal axes. Panel A shows the planned trial design, Panel B the actual one. Calender week 33 (vertical axes) corresponds to mid August 2011 (15.0821.08.2011) and calender week 46 to mid November (14.11.-20.11.2011). Accordingly, week 0 on the horizontal axes refers to mid August 2011 (15.08-21.08.2011), week 13 to mid November (14.11.-20.11.2011).

The procuring authority aimed to attract a number of qualified bidders large enough to establish a nationwide network of other actors consisting of at least five suppliers per target group per employment region. To meet this goal, 17 other actors were eventually awarded a contract (framework agreement). According to the Act on Active Employment Initiatives as of December 2009, job centers were then bound to refer all newly-registered unemployed with long-cycle higher education to one of the other actors chosen for execution of a contract. Private providers were not allowed to reject individuals referred to them; cream skimming was not an option. Regarding the timing of the referral, unemployed below the age of 30 had to be referred to an other actor within the first six weeks of unemployment, those older than 30 within the first three months. Municipal job centers had to refer target group members to the provider that they deem most qualified to deliver the required services. If several actors were considered equally effective (taking price, quality, prior performance, individual needs, and local conditions into account), the choice was up to the unemployed. 
Contracted Services Private placement agencies were supposed to help their clients back to work as fast as possible using an active and employment-oriented strategy. Procurement contracts specified that other actors had to be in contact with their clients at least once a quarter; the clients' CVs had to be updated on a regular basis; and, lastly, unemployed had to participate in active labour market programs during at least 40 percent of the time that they were enrolled. As to this latter requirement, active instruments include classroom training, participation in job counseling programs (job search and job readiness training), subsidized employment with private or public employers (for a period not longer than one year), temporary work experience in the private or public sector (up to four weeks), and short education or vocational training programs chosen by the unemployed themselves (courses of up to six weeks' duration). ${ }^{7}$

Apart from these requirements, a key principle of the Danish contracting out system is freedom of method: other actors have the authority to organize the complete array of placement services for their clients and the freedom to use their own approach within the limits of general provisions and restrictions. ${ }^{8}$ Freedom of method is a two-edged sword: on the one hand, it is a prerequisite for flexibility and innovation; the absence of precise guidelines for service delivery, on the other hand, creates the opportunity to save costs and allows contractors to act in their own best interest. These considerations obviate the need for a high-powered incentive mechanism.

Incentives Bidders had to offer a total price per job-seeker per target group per year. The price (100 percent) was composed of an operation subsidy (25 percent) and a performance based bonus component (75 percent). The two-tier payment model is rich in detail and rather complex. Since providing a fully comprehensive description adds little to our discussion, we present its core elements in a slightly simplified form. ${ }^{9}$ In any case, the objective of the incentive scheme sketched below was to ensure that activities are targeted at helping the unemployed back to work, above all into regular employment, as fast as possible.

The operation subsidy for the contract period of 52 weeks amounted to 25 percent of the contracted price. The subsidy was granted in equal shares for each week a job-seeker was enrolled with the other actor, unless the client was employed for more than 20 hours in a given week. ${ }^{10}$ The performance based bonus component made up for the remaining 75 percent of the price (big bonus). In order to qualify for a big bonus a client had to be placed in regular employment for at

\footnotetext{
${ }^{7}$ It is worth noting that temporary work experience, subsidized employment, and self-chosen education are not associated with direct costs for private providers. Wage subsidies for clients in subsidized employment as well as short education or vocational training programs chosen by the unemployed themselves are paid by public authorities. Regarding temporary work experience, this program is free of charge: participants receive the benefit they would normally receive, but no wage, so the program entails no direct costs for the "employer" neither.

${ }^{8}$ The responsibility to determine benefit eligibility remained with public authorities. Similarly, the decision to exempt a client (upon request) from otherwise compulsory activation activities was to be made by the job center.

${ }^{9}$ The interested reader is referred to the tender documents (Arbejdsmarkedsstyrelsen, 2010).

${ }^{10}$ Letting $p^{c}$ denote the contracted price, the per-week payment for each enrolled, but not currently employed client equals $(1 / 52) *(1 / 4) * p^{c}$.
} 
least 20 hours per week for a total of 13 weeks within the last six months. In case of subsidized employment, a small bonus would be granted, but only for subsidized employment with a private employer; two small bonuses are equivalent to one big bonus. It was possible to obtain more than one bonus per client - and therewith more than 100 percent of the agreed-upon price - since the bonus count (counting the number of weeks in employment) was reset each time the bonus target (13 weeks within the last six months) was reached. However, for a single, uninterrupted employment spell, only one bonus could be granted regardless of the spell's length.

Figure 3 shows the distribution of contracted prices by target group. It is immediately seen that mean prices are almost identical ( 15,000 DKK per client per year). ${ }^{11}$ The same applies to the medians, which surpass the means by approximately 500 DKK. The small price differentials suggest that bidders did not hold the belief that one of the two target groups is relatively more employable and thus easier to place, or that one of the two groups is more responsive to their counseling technology. If such a belief existed, bidders would have in all likelihood demanded a price premium for the other group. This is not what we observe. In fact, against the conventional wisdom that young job-seekers tend to be easier to place, the largest price ( 17,500 DKK) was contracted for younger, and the smallest price $(\sim 10,500 \mathrm{DKK})$ for older clients. To put these magnitudes into perspective, notice that 15,000 DKK correspond to around 30 percent of mean standardized monthly earnings of workers with long-cycle higher education in Denmark. ${ }^{12}$

Figure 3: Contracted prices per job-seeker per year by target group

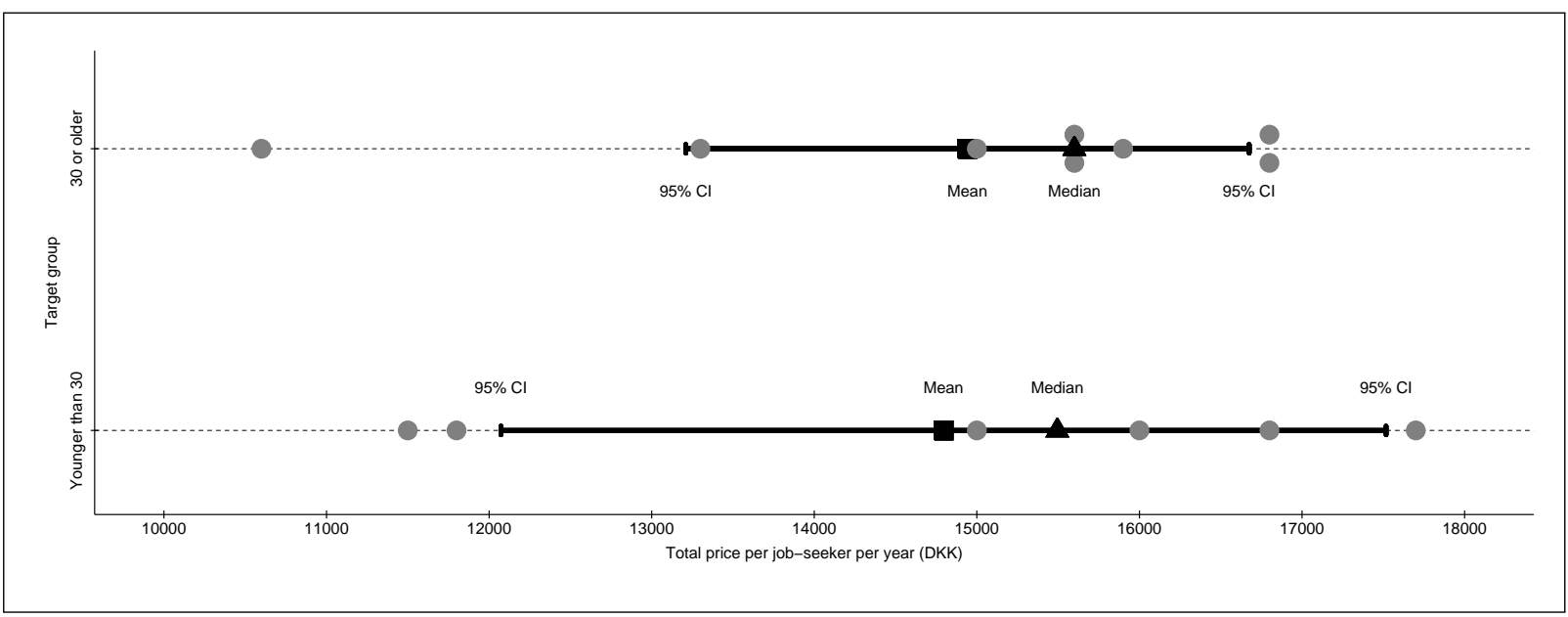

Notes: The figure shows the distribution of contracted prices by target group. Each dot represents a contracted price. The unit of observation is the individual private provider. Prices are in Danish Kroner (DKK). Price data stem from the governing body ("brancheforening") of private other actors in Denmark. Not all private providers that have been awarded a service contract in the 2010 tendering round are affiliated with this organization, and just some its members disclosed their price.

Besides the financial incentives described above, other actors may have been motivated by reputation incentives, which were induced by the fact that public authorities publicized provider-

\footnotetext{
${ }^{11}$ In 2012, 1 Danish Krone (DKK) corresponded to 5.79 US Dollar or 7.44 Euro (yearly average exchange rates).

${ }^{12}$ The statistic refers to 2010 and stems from Statistics Denmark's Statistical Yearbook 2012 (Table 118).
} 
specific performance indicators online. The key performance measure was the average number of big bonus equivalents granted per enrolled job-seeker, the so-called "bonus share". A private provider's performance and reputation could, in principle, also play a role to be re-awarded a contract in future procurements.

\section{Data and Descriptive Statistics}

Data The bulk of our empirical analysis is based on an experiment-specific administrative dataset which we complement with information from the so-called DREAM database. The experiment-specific administrative dataset contains information on the individual treatment status, the participants' affiliation with job centers and other actors, the date of intake, as well as the number and timing of meetings. Using social security numbers as identifiers, we merge this dataset with the DREAM database. The DREAM database integrates data from several sources, among others the Civil Registration System, the Ministry of Employment, and Danish tax authorities. It is a rich longitudinal database that includes records for all individuals who received some kind of welfare benefit within the last two decades. It encompasses individual demographic information (age, gender, cultural origin, marital status, etc.), weekly data on the type of welfare benefit receipt (if any), as well as information on participation in active labour market programs. Moreover, by linking the DREAM database with the "eIndkomst register" (electronic income register), we are able to identify episodes of regular (i.e. wage) employment.

Note that Danish register data is known to be of very high quality (Thygesen, Daasnes, Thaulow, and Brønnum-Hansen, 2011): coverage is virtually universal and different registers can be linked at the individual level. By using high-quality register data we avoid some of the pitfalls of survey data, such as sample attrition caused by item nonresponse; recall bias; and misreporting. Exploring longitudinal register data also allows us to go beyond a single baseline and a single follow-up. In fact, given weekly data, we do have substantially "more T": data available to us reach back to 2000 (11 pre-trial years); the follow-up period, measured from the individual week of intake, ranges between 67 and 80 weeks. The effect analysis presented in this paper is therefore confined to the short to medium term.

Using DREAM data and information from the income register, we construct four outcome variables: a set of three positive and one negative outcomes. The first positive outcome is regular employment, which we define as the incidence of receiving wage payments for employment subject to social insurance contributions. We do, unfortunately, only observe whether an individual receives such wage payments in a given week, but we cannot observe the wage itself. The second employment outcome is subsidized employment. As mentioned earlier, one can differentiate between subsidized employment in the private and subsidized employment in the public sector. 
Recall further that placing clients into subsidized jobs is one of the two contracted outcomes for which a bonus could be granted (regular employment being the other one). While subsidized jobs are always temporary (not longer than six months with a public, 12 months with a private employer), they can act as a stepping stone towards more permanent employment relationships. This is why we consider this type of employment a positive outcome. The third outcome variable is labeled "non-benefit receipt": it encompasses individuals in regular employment, as well as self-employed, housewives, and everybody else not receiving public income transfers (expats, the deceased, etc.). The last outcome we consider, the negative one, is unemployment, defined as the receipt of unemployment or social assistance benefits. ${ }^{13}$ Table A2 in the Appendix lists the DREAM codes associated with each of our four main outcome variables.

Balancing Tests Table 2 presents summary statistics (means and standard deviations) for several pre-treatment variables. The table groups variables into categories and lists them under three headings: socio-demographic characteristics; individual labour market history; type of welfare benefit receipt in the week before enrolment. Means and standard deviations are presented separately for job-seekers randomized into private and job-seekers randomized into public employment services. The table's rightmost column displays the difference in group means and tests the null hypothesis that the means are equal in both groups.

The first panel shows that socio-demographic characteristics are by and large balanced between treated and controls. There are, however, some minor differences in the age composition of the two groups: while 47 percent of all controls were younger than 30, this was the case for "only" 43 percent of all treatment group members. The treatment group's relative shortfall in the younger-than-30 age group is compensated by a relative abundance in the age bracket directly above. Individuals assigned to public services are, on average, one and a half months older than their peers in the control group (not shown); this difference is small in magnitude and insignificant (p-value: 0.674). ${ }^{14}$ The second panel summarizes the trial participants' individual labour market histories in the three years prior to the experimental intervention. Individuals assigned to private services, for instance, were employed for 13.9 weeks on average in the second last year before enrolment, compared with an average of 15.1 weeks for those assigned to public services; the difference of 1.2 weeks is borderline significant (p-value: 0.099). Individuals in the public track also show higher employment levels in the year preceding randomization (five days), but this differential is statistically insignificant. Postulating that most recent employment rates are the best predictor for future performance, this suggests that there is no significant difference in

\footnotetext{
${ }^{13}$ It is worth noting that subsidized employment and unemployment are not mutually exclusive. In particular, we regard (almost all) individuals in a subsidized job as being unemployed, see Table A2 in the Appendix.

${ }^{14}$ We also performed a two-sample Kolmogorov-Smirnov test for equality of the age distributions, the result of which suggests that the two samples have been drawn from the same population (null hypothesis: equality of distributions; p-value: 0.331 ).
} 
Table 2: Means of pre-treatment characteristics by assignment status

\begin{tabular}{|c|c|c|c|c|c|}
\hline \multirow{2}{*}{ Variable } & \multicolumn{2}{|c|}{ Private } & \multicolumn{2}{|c|}{ Public } & \multirow{2}{*}{ Difference } \\
\hline & Mean & Std. dev. & Mean & Std. dev. & \\
\hline \multicolumn{6}{|l|}{ Panel A: Socio-demographic characteristics } \\
\hline Male & 0.395 & $(0.489)$ & 0.421 & $(0.494)$ & 0.026 \\
\hline Married & 0.294 & $(0.456)$ & 0.306 & $(0.461)$ & 0.012 \\
\hline Danish origin & 0.852 & $(0.355)$ & 0.856 & $(0.351)$ & 0.003 \\
\hline Western origin & 0.085 & $(0.279)$ & 0.089 & $(0.285)$ & 0.004 \\
\hline Non-western origin & 0.063 & $(0.242)$ & 0.055 & $(0.228)$ & -0.007 \\
\hline$<30$ years old & 0.466 & $(0.499)$ & 0.432 & $(0.495)$ & $-0.034^{*}$ \\
\hline $30-39$ years old & 0.349 & $(0.477)$ & 0.387 & $(0.487)$ & $0.038^{* *}$ \\
\hline $40-49$ years old & 0.117 & $(0.321)$ & 0.116 & $(0.320)$ & -0.001 \\
\hline$>49$ years old & 0.069 & $(0.253)$ & 0.066 & $(0.249)$ & -0.003 \\
\hline \multicolumn{6}{|l|}{ Panel B: Labour market history (weeks) } \\
\hline Education in year before trial & 21.020 & $(22.602)$ & 20.392 & $(22.419)$ & -0.628 \\
\hline Education in 2nd last year before trial & 26.222 & $(24.672)$ & 25.416 & $(24.902)$ & -0.806 \\
\hline Education in 3rd last year before trial & 26.485 & $(24.916)$ & 25.772 & $(24.894)$ & -0.713 \\
\hline Employment in year before trial & 13.623 & $(18.471)$ & 14.406 & $(18.793)$ & 0.782 \\
\hline Employment in 2nd last year before trial & 13.858 & $(20.508)$ & 15.088 & $(21.050)$ & $1.230^{*}$ \\
\hline Employment in 3rd last year before trial & 13.879 & $(20.793)$ & 14.968 & $(21.374)$ & 1.088 \\
\hline Unemployment in year before trial & 7.195 & $(9.918)$ & 7.486 & $(10.369)$ & 0.291 \\
\hline Unemployment in 2 nd last year before trial & 3.925 & $(9.639)$ & 3.473 & $(9.270)$ & -0.452 \\
\hline Unemployment in 3rd last year before trial & 2.708 & $(8.580)$ & 2.430 & $(8.007)$ & -0.278 \\
\hline \multicolumn{6}{|c|}{ Panel C: Type of welfare benefit received in the week before intake } \\
\hline Unemployment benefits & 0.701 & $(0.458)$ & 0.694 & $(0.461)$ & -0.006 \\
\hline Education grants & 0.071 & $(0.257)$ & 0.058 & $(0.235)$ & -0.012 \\
\hline Other benefit & 0.098 & $(0.297)$ & 0.114 & $(0.318)$ & 0.017 \\
\hline No benefit & 0.131 & $(0.337)$ & 0.133 & $(0.340)$ & 0.002 \\
\hline Number of observations & \multicolumn{2}{|c|}{1,566} & \multicolumn{2}{|c|}{1,541} & \\
\hline
\end{tabular}

Notes: The table shows means and standard deviations of pre-treatment characteristics by assignment status. The difference in group means in the last column is obtained by regressing the variables in the first column on a treatment status indicator. Significance levels are calculated using the standard errors of the estimated coefficients; this is equivalent to performing an independent samples two-sided t-test.

Significance levels: ${ }^{*} p<0.10,{ }^{* *} p<0.05,{ }^{* * *} p<0.01$

baseline employment prospects. Overall, pre-treatment characteristics appear to be similar and well-balanced. ${ }^{15}$ Nonetheless, in the analysis below we control for background characteristics to ensure balance and to boost precision.

Further insight into the pre-trial labour market experiences of the two groups is provided in Figure 4, which shows how the distribution of trial participants across various labour market states evolved during the 65 weeks before randomization. From the graph it is apparent that pre-trial distributional patterns for treated and controls are very similar. In both groups, around two sixths of all individuals received no benefits 65 weeks before randomization; three sixths received education grants; and the remaining sixth was either unemployed, receiving maternity benefits, or registered in some other status. Both distributions remain relatively stable for most of the period. Around four months before randomization, however, the steady decrease in the number of individuals claiming education grants initiates a rapid increase in unemployment

\footnotetext{
${ }^{15}$ We have also checked whether pre-treatment characteristics help to explain treatment assignment - they do not. In particular, we ran a regression of the treatment status indicator on all pre-treatment variables shown in Table 2. Based on an F-test (p-value: 0.418), we fail to reject the null that they are jointly insignificant.
} 
benefit receipt, which eventually peaks at 83 percent in the week of intake. It is immediately seen that the trajectories are remarkably similar in both groups. Evidently, we are comparing comparable individuals.

Figure 4: Pre-trial labour market trajectories by assignment status

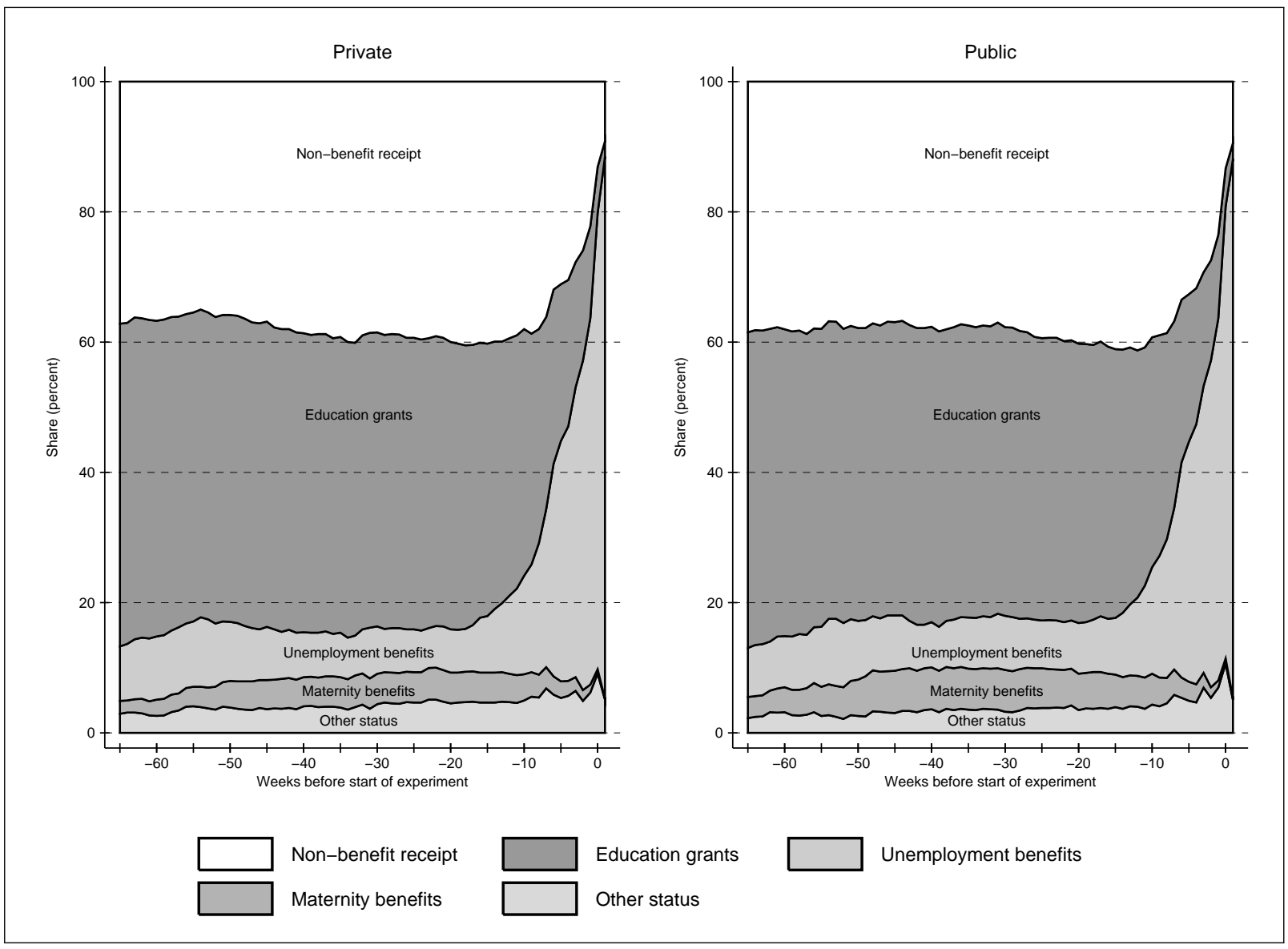

Notes: The figure shows the week-by-week share of individuals in various labour market states by assignment status for the 65 weeks before random assignment. By construction, shares add up to 1 . Week 0 corresponds to the week before randomization; the horizontal axes extend to week 1.

Working Methods The aim of this section is to provide an answer to the question whether private contractors and public job centers use different approaches to providing employment services. For this purpose, we utilize weekly data on meetings between clients and caseworkers, as well as weekly information on participation in active labour market programs.

Regarding meetings first, Figure 5 plots histograms for the total number of meetings per individual over the course of the experiment by treatment status. In both groups, 15 percent of all individuals did not participate in any meeting at all. It is worth noting that private providers had a strong incentive to initiate a first meeting because the reward system ruled out bonus payments for clients who never showed up, whereas clients who did have a meeting could generate bonuses even if they found a job on their own. Therefore, one may have expected the share of individuals with no meeting to be relatively small in the private program, which is not 
the case. Apart from that, the distribution for individuals receiving private services appears to have less mass on the left and a longer tail to the right, pointing to a higher meeting frequency for this group. Regressing the number of meetings per individual on a treatment status indicator shows that job-seekers assigned to the public program had about half a meeting less on average than individuals in the private track. This difference is highly statistically significant (p-value: 0.000 ) and corresponds to a relative decrease of almost 20 percent. ${ }^{16}$

Figure 5: Number of meetings held by assignment status

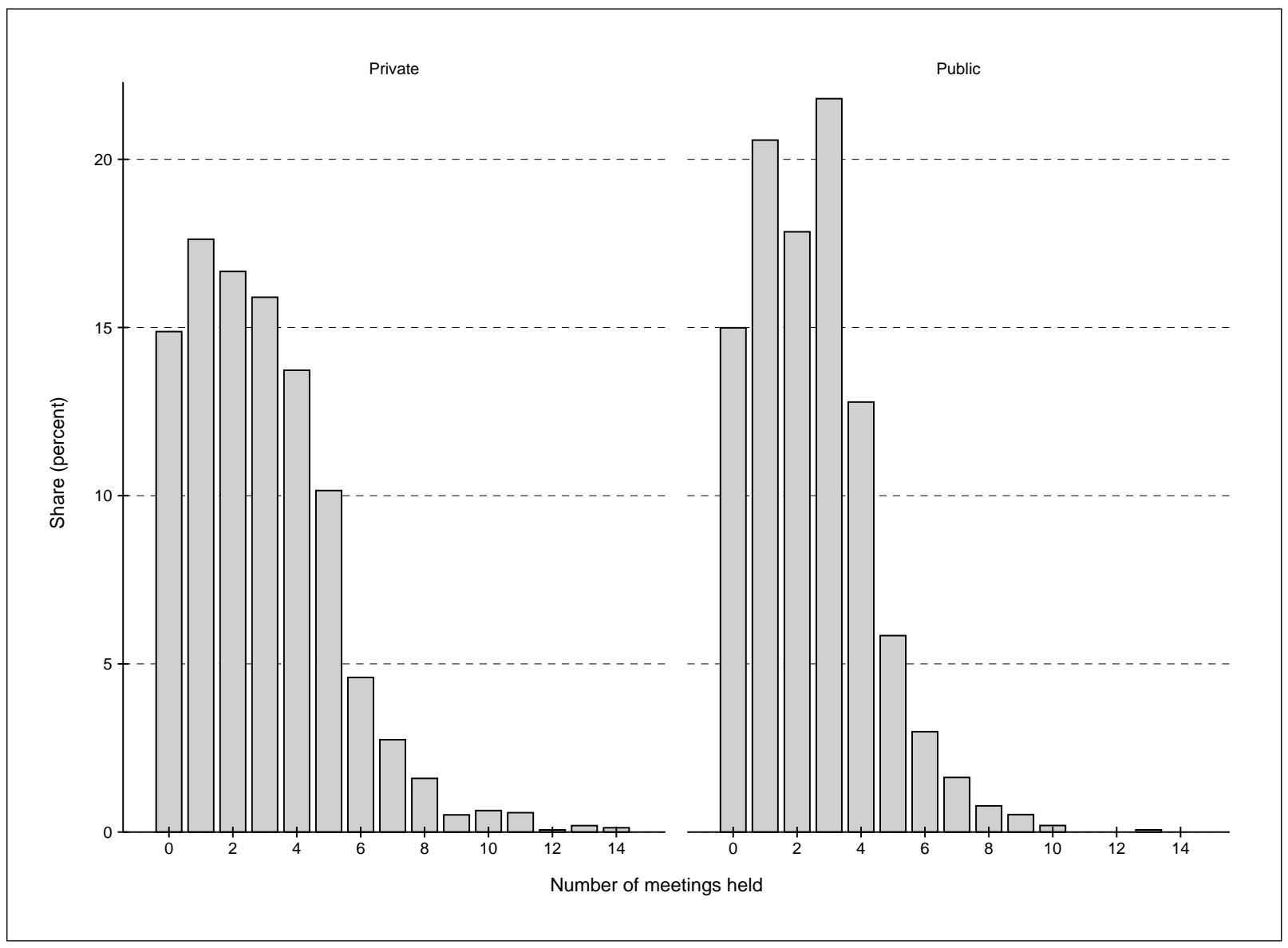

Notes: The figure shows histograms for the total number of meetings held per individual between the individual week of intake and the end of June 2012 by assignment status.

Next, regarding participation in active labour market programs, Table 3 displays the number of "ALMP spells" (number of programs) and the "ALMP incidence" (number of program weeks) by assignment status, as well as statistics on the programs' timing and duration. There are three things to note. First, individuals assigned to privately provided services participated in more active labour market programs and tended to be "active" during more weeks than individuals assigned to public services. Panel B illustrates for instance that unemployed referred to private contractors participated in active labour market programs for eight weeks on average over the course of experiment, compared with seven weeks for unemployed who received public services. That individuals randomized into private services participated in more programs on average (1.4

\footnotetext{
${ }^{16}$ Individuals in the public program had two and a half meetings on average.
} 
versus 1.2 spells) is shown in Panel A. Second, the timing differs: while the mean program duration is identical for both groups (seven weeks), programs organized by private contractors started two weeks earlier on average than those initiated by the public employment service. And thirdly, private and public providers prioritized different activities. The general picture is that the private "treatment portfolio" appears to be more employment-oriented: for individuals at private providers, temporary work experience and subsidized employment account for 42 percent of all programs and 54 percent of all program weeks, while the comparable rates for the public track are 33 and 46 percent, respectively. ${ }^{17}$ Public job centers, in turn, relied relatively more on job counseling, classroom training, and self-chosen education. ${ }^{18} \mathrm{In}$ sum, private providers deliver more intense, employment-oriented, and earlier services. That being said, client satisfaction is still slightly higher in the public track. ${ }^{19}$

\section{$5 \quad$ Empirical Approach and Results}

Empirical Strategy In order to compare the effectiveness of private and public providers of employment services, we estimate the following model:

$$
Y_{i}=\alpha_{1}+\delta \text { Public }_{i}+\mathbf{X}_{\mathbf{i}} \boldsymbol{\beta}_{\mathbf{1}}+\varepsilon_{1 i}
$$

where $Y_{i}$ is the labour market outcome of individual $i$, Public $i$ is equal to unity for clients assigned to the public program (zero otherwise), and $\mathbf{X}_{\mathbf{i}}$ is the vector of pre-treatment characteristics summarized in Table 2 . The coefficient $\delta$ corresponds to the difference in group means of outcome $Y$ between individuals assigned to public and individuals assigned to private services (conditional on $\mathbf{X})$. It identifies the intention-to-treat effect $E\left(Y_{i} \mid\right.$ Public $\left._{i}=1, \mathbf{X}_{\mathbf{i}}\right)-E\left(Y_{i} \mid\right.$ Public $\left._{i}=0, \mathbf{X}_{\mathbf{i}}\right)$ provided that $E\left(\varepsilon_{1 i} \mid\right.$ Public $\left.c_{i}, \mathbf{X}_{\mathbf{i}}\right)=E\left(\varepsilon_{1 i} \mid \mathbf{X}_{\mathbf{i}}\right)$, that is provided that the two groups are balanced on relevant unobservables. Given random assignment, this seems plausible.

Main Results Table 4 displays the intention-to-treat effects of offering public instead of private employment services on regular employment, subsidized employment, non-benefit receipt, and unemployment. We report estimates obtained both with and without controls, and, to begin with, we evaluate the effect on labour market outcomes at four different points in time. First, 13

\footnotetext{
${ }^{17}$ The difference between the statistic reported here $(33$ percent) and the statistics displayed in Table $3(12+$ $8+4+11=35)$ is due to rounding.

${ }^{18}$ We have also checked to which degree the differences in treatment priorities apparent from Table 3 influenced the individual likelihood to participate in different programs. In particular, we have regressed program participation indicators on a treatment status dummy. Our findings suggest that individuals assigned to public services were less likely to participate in all activities, except classroom training. For brevity, we report only those effects that are statistically significant at conventional levels ( $\mathrm{p}$-values in parentheses): individuals assigned to public services were 3.5 percentage points less likely to participate in an active labour program over the course of the experiment (0.043); 3.6 percentage points more likely to attend classroom training (0.000); and, lastly, 9.1 percentage points less likely to gather temporary work experience in the private sector $(0.000)$.

${ }^{19}$ This latter result is discussed in greater detail in Rambøll (2012).
} 
Table 3: Participation in active labour market programs by assignment status

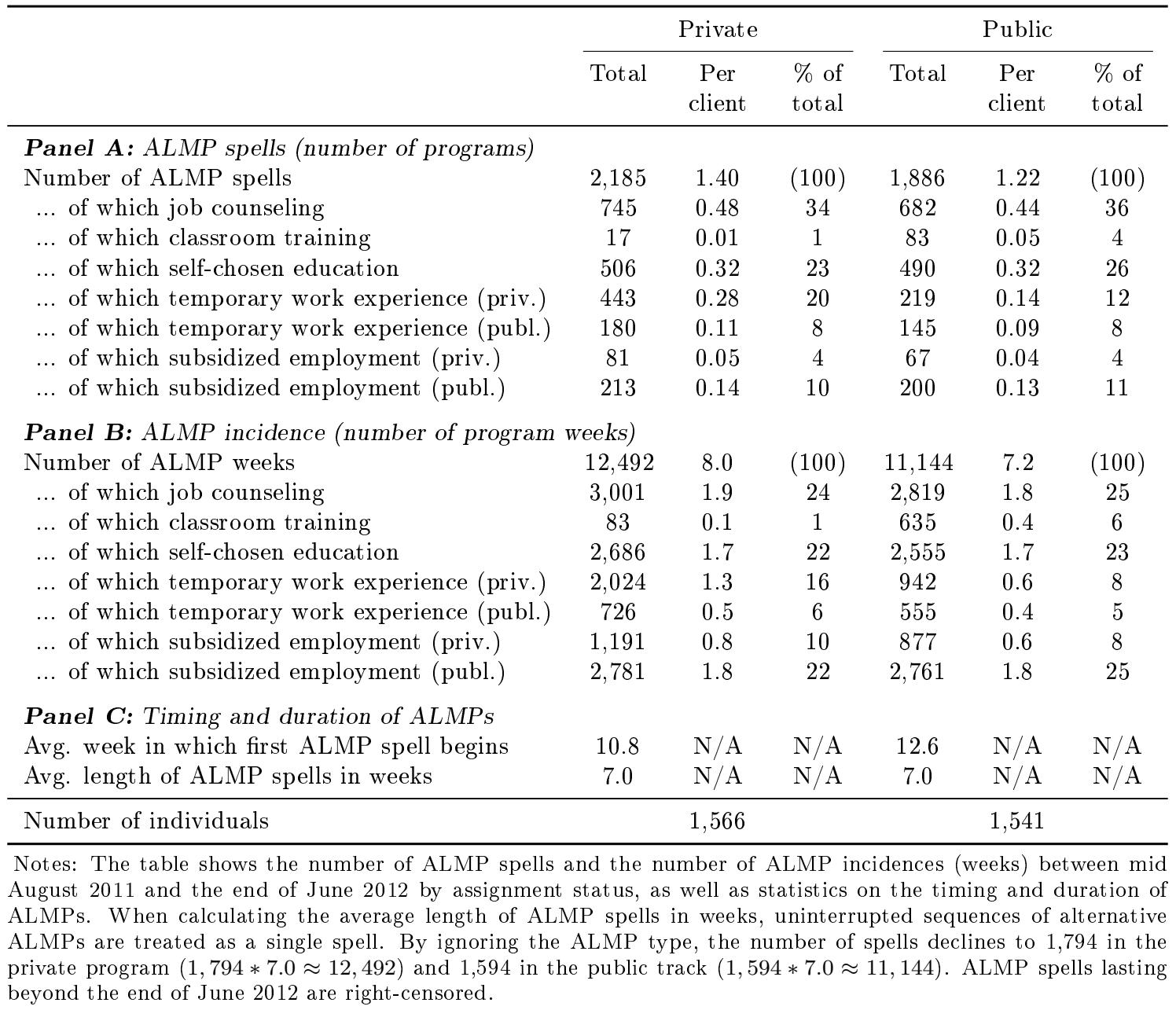

weeks after randomization, to capture short-run performance differentials between private and public service providers. Second, at the assignment period's end in the end of June 2012, after which both groups received public services in case of continued unemployment. Third, 52 weeks after random assignment: one year after intake, a medium-run perspective. And fourth, 67 weeks after enrolment, which is the last week during which we still observe all trial participants.

As it becomes evident from Panel A, there are no statistically significant differences in labour market outcomes between treated and controls 13 weeks after randomization. Column (1) shows that 23.6 percent of job-seekers assigned to private services were employed in a regular job 13 weeks after enrolment ("Mean private"); those assigned to public services were 0.4 percentage points less likely to be employed ("Assigned public"), but this effect is statistically indistinguishable from zero. Controlling for the background characteristics summarized in Table 2 results in a slightly larger point estimate (in absolute terms) that still falls short of statistical significance (column (2)). Similarly, the effects of being assigned to a public provider on subsidized employment and non-benefit receipt are insubstantial and insignificant. While the point estimate for unemployment is somewhat larger (one percentage point), it is far away from being statistically significant too (p-value without controls: 0.579 ; with controls: 0.455 ). 
Table 4: The effect of offering public instead of private employment services on various labour market outcomes (intention-to-treat)

\begin{tabular}{|c|c|c|c|c|c|c|c|c|}
\hline & \multicolumn{2}{|c|}{$\begin{array}{c}\text { Regular } \\
\text { employment }\end{array}$} & \multicolumn{2}{|c|}{$\begin{array}{c}\text { Subsidized } \\
\text { employment }\end{array}$} & \multicolumn{2}{|c|}{$\begin{array}{l}\text { Non-benefit } \\
\text { receipt }\end{array}$} & \multicolumn{2}{|c|}{ Unemployment } \\
\hline & (1) & $(2)$ & $(3)$ & $(4)$ & $(5)$ & (6) & $(7)$ & (8) \\
\hline \multicolumn{9}{|c|}{ Panel A: After 3 months (13 weeks) } \\
\hline Assigned public & $\begin{array}{l}-0.4 \\
(1.5)\end{array}$ & $\begin{array}{l}-0.7 \\
(1.5)\end{array}$ & $\begin{array}{c}0.2 \\
(0.6)\end{array}$ & $\begin{array}{c}0.2 \\
(0.6)\end{array}$ & $\begin{array}{l}-0.0 \\
(1.7)\end{array}$ & $\begin{array}{l}-0.4 \\
(1.6)\end{array}$ & $\begin{array}{c}1.0 \\
(1.8)\end{array}$ & $\begin{array}{c}1.3 \\
(1.7)\end{array}$ \\
\hline Controls & No & Yes & No & Yes & No & Yes & No & Yes \\
\hline Mean private & 23.6 & 23.6 & 3.3 & 3.3 & 30.8 & 30.8 & 60.0 & 60.0 \\
\hline \multicolumn{9}{|c|}{ Panel B: At the end of the assignment period } \\
\hline Assigned public & $\begin{array}{c}0.6 \\
(1.8)\end{array}$ & $\begin{array}{c}0.2 \\
(1.7)\end{array}$ & $\begin{array}{l}-1.1 \\
(1.1)\end{array}$ & $\begin{array}{l}-0.9 \\
(1.1)\end{array}$ & $\begin{array}{l}-0.1 \\
(1.8)\end{array}$ & $\begin{array}{l}-0.6 \\
(1.8)\end{array}$ & $\begin{array}{c}1.2 \\
(1.7)\end{array}$ & $\begin{array}{c}1.7 \\
(1.7)\end{array}$ \\
\hline Controls & No & Yes & No & Yes & No & Yes & No & Yes \\
\hline Mean private & 43.9 & 43.9 & 10.2 & 10.2 & 53.1 & 53.1 & 36.4 & 36.4 \\
\hline \multicolumn{9}{|c|}{ Panel C: After 12 months (52 weeks) } \\
\hline Assigned public & $\begin{array}{c}1.4 \\
(1.8)\end{array}$ & $\begin{array}{c}0.9 \\
(1.7)\end{array}$ & $\begin{array}{c}-1.9^{* *} \\
(0.9)\end{array}$ & $\begin{array}{c}-1.8^{*} \\
(0.9)\end{array}$ & $\begin{array}{c}2.0 \\
(1.8)\end{array}$ & $\begin{array}{c}1.4 \\
(1.7)\end{array}$ & $\begin{array}{l}-1.3 \\
(1.6)\end{array}$ & $\begin{array}{l}-0.8 \\
(1.6)\end{array}$ \\
\hline Controls & No & Yes & No & Yes & No & Yes & No & Yes \\
\hline Mean private & 48.4 & 48.4 & 8.4 & 8.4 & 58.0 & 58.0 & 30.7 & 30.7 \\
\hline \multicolumn{9}{|c|}{ Panel D: After 15 months (67 weeks) } \\
\hline Assigned public & $\begin{array}{c}1.3 \\
(1.8)\end{array}$ & $\begin{array}{c}0.9 \\
(1.7)\end{array}$ & $\begin{array}{l}-1.4 \\
(0.8)\end{array}$ & $\begin{array}{l}-1.3 \\
(0.8)\end{array}$ & $\begin{array}{c}1.4 \\
(1.7)\end{array}$ & $\begin{array}{c}1.1 \\
(1.7)\end{array}$ & $\begin{array}{l}-0.8 \\
(1.5)\end{array}$ & $\begin{array}{l}-0.6 \\
(1.5)\end{array}$ \\
\hline Controls & No & Yes & No & Yes & No & Yes & No & Yes \\
\hline Mean private & 53.3 & 53.3 & 6.6 & 6.6 & 64.4 & 64.4 & 24.8 & 24.8 \\
\hline
\end{tabular}

Notes: The table displays the effect of being assigned to public instead of private employment services measured in percentage points, see equation (1). Panel A evaluates the effect 13 weeks after randomization, Panel B at the end of the assignment period (in the end of June 2012), Panel C 52 weeks, and Panel D 67 weeks after randomization. Outcome variables are described in Chapter 4. Control variables are the pre-treatment characteristics summarized in Table 2 (with age entering linearly, not as dummy-coded categorical predictor). "Mean private" refers to the mean of the corresponding outcome among individuals assigned to private services. Robust standard errors in parentheses. 3,107 observations.

Significance levels: ${ }^{*} p<0.10,{ }^{* *} p<0.05,{ }^{* * *} p<0.01$

At the assignment period's end, Panel B, we find that already more than half of all trial participants reached self-sufficiency, i.e. they did not claim any benefits. Further, the unemployment rate declined from more than 80 percent in the week of intake to 36.4 percent among assigned-to-private individuals, and 37.6 percent in the public program (1.2 percentage points more). As before, differences between the two groups are small in magnitude and insignificant. When expressed in relative terms, however, the effect of being assigned to the public program on subsidized employment stands out: the differential of -1.1 percentage points displayed in column (3) corresponds to a relative decrease of more than ten percent ( $\mathrm{p}$-value: 0.315 ).

One year after randomization, Panel C, individuals at public providers were 1.4 percentage points more likely to have a job subject to social insurance contributions, column (1), but 1.9 percentage points less likely to have a subsidized job, column (3). This latter effect is statistically significant at the five percent level and it is robust to the inclusion of additional controls, column (4). Note that this finding corresponds well with our previous result that private providers prioritize employment-oriented activities, such as subsidized employment. 
Finally, at the end of our observation period, Panel D, individuals in the public program exhibit an employment rate 1.3 percentage points above the counterfactual rate in the private track (54.5 versus 53.3 percent - rounded); a higher level of non-benefit receipt (1.4 percentage points); and a slightly lower unemployment rate (24 vis-à-vis 24.8 percent). The share of individuals with a subsidized job, on the other hand, was still smaller than in the private program. It should be noted, however, that none of these differences is statistically significant at conventional levels.

Taken all together, the intention-to-treat effects reported in Table 4 do not provide a clear answer as to whether the overall return of being referred to a public provider instead of being assigned to the private track was positive or negative on average. First, differences in labour market outcomes between the two groups are generally small in magnitude, never exceeding two percentage points, and falling short of one percentage point in every second instance. Second, just two of the 32 point estimates presented in Table 4 are statistically significant at conventional levels; in fact, only few of the estimates exceed their standard errors (one in six does). Third, even when taken at face value, no clear picture emerges from the multitude of estimates presented above. For regular employment, non-benefit receipt, and unemployment we find negative effects of being with a public provider in the short run, but eventually favorable effects at later stages. For subsidized employment, in turn, it is exactly the other way around. And lastly, it is important to bear in mind that the intention-to-treat effects reported in Table 4 represent "snapshots" only, assessing the relative merits of private and public provision of employment services at arbitrarily chosen points in time. In order to provide a more complete picture of the trajectory of treatment effects, we present week-by-week estimates in Figure 6.

Figure 6 is composed of eight panels. The four panels on the left show, for each week after random assignment (week by week), the share of trial participants in various labour market states by assignment status. The four panels on the right plot the difference in these shares (public versus private), and thereby trace out the trajectory of treatment effects over time (controlling for background characteristics). The solid lines represent the week-by-week effect of offering public instead of private employment services, measured in percentage points, together with a 95 percent confidence interval. Each of the four right-hand side panels is based on 67 separate regressions using the model specified in equation (1): we regress, separately for each week, the corresponding outcome on an assignment status indicator $\left(\right.$ Public $\left._{i}\right)$ and the timeinvariant vector of controls shown in Table $2\left(\mathbf{X}_{\mathbf{i}}\right)$. In addition to the "Week-by-week effect", we also report the "Average effect over all weeks" (dashed line). This statistic could, in principle, be calculated manually by averaging the week-by-week effects across all weeks (i.e. by smoothing out the solid lines), or, which amounts to the same thing, by estimating the following pooled model:

$$
Y_{i t}=\alpha_{2}+\bar{\delta} P u b l i c_{i}+\mathbf{X}_{\mathbf{i}} \boldsymbol{\beta}_{\mathbf{2}}+\mathbf{T} \boldsymbol{\lambda}+\varepsilon_{2 i t}
$$


Figure 6: Week-by-week share of trial participants in various labour market states by assignment status (left) and the effect of offering public instead of private services (right)

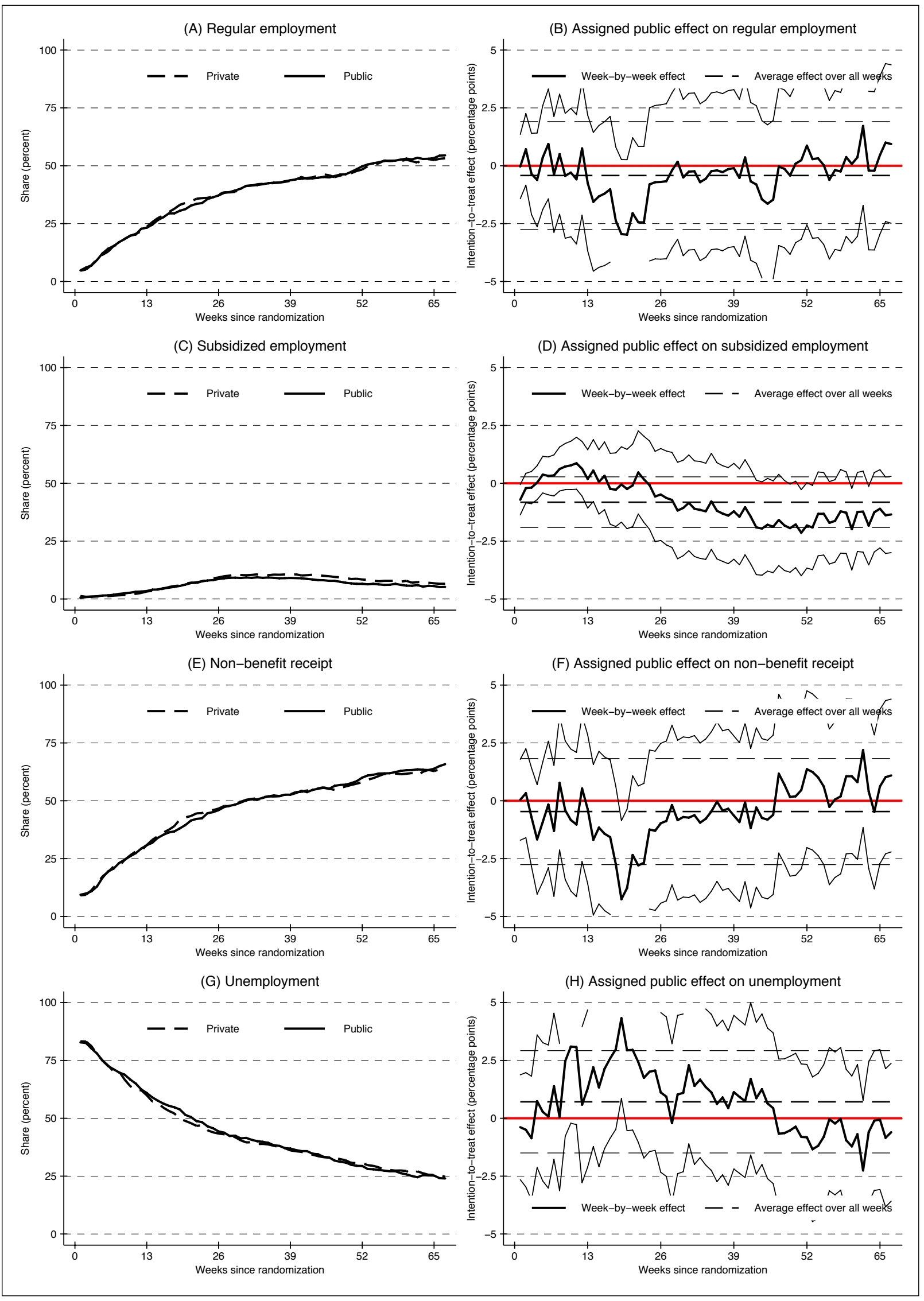

Notes: Left-hand side panels show raw means by assignment status. Right-hand side panels display the effect of being assigned to public instead of private employment services measured in percentage points together with a 95 percent confidence interval; see equation (1) for the week-by-week effect, and equation (2) for the average effect over all weeks. Confidence bounds are censored at \pm five percentage points for illustrational purposes. 
where $Y_{i t}$ now denotes the labour market outcome of client $i$ in week $t$ after randomization, and $\mathbf{T}$ is a vector of 67 weeks-since-randomization dummies. The coefficient $\bar{\delta}$ captures the average difference in labour market outcome $Y$ between individuals assigned to public and individuals assigned to private services across all weeks. Following Laun and Thoursie (2014), we cluster standard errors at the individual level to control for errors that are correlated within clusters. ${ }^{20}$ The cluster-robust standard errors are then used to construct a 95 percent confidence intervall for the "average-over-all-weeks effect" $\bar{\delta}$, see Figure 6.

For the outcome variables regular employment and non-benefit receipt, Panel B and Panel F, week-by-week intention-to-treat effects appear to oscillate with relatively small amplitudes around a zero-effect during the first 13 weeks after randomization. During the next three months, individuals assigned to public services were up to three percentage points less likely to be in contributory employment than individuals in the private program (p-value in week 20: 0.072), and up to 4.3 percentage points less likely to be self-sufficient. Noteworthy, the effect on nonbenefit receipt reaches statistical significance at the five percent level in weeks 19 and 20. At 26 weeks, however, both effects have petered out, and they remain small over the course of the next quarter. It is only towards the end of our observation window that the effects regain momentum, but now with a tendency to favor job-seekers assigned to the public track. Overall, we find that individuals at public providers were - on average across all weeks - 0.4 percentage points less likely to be regularly employed than individuals assigned to private services, and 0.5 percentage points less likely to not receive any transfer payments (non-benefit receipt). These effects are statistically insignificant and of small magnitude: expressed in terms of "number of weeks employed during follow-up" (i.e. during 67 weeks), the (minus) 0.4 percentage points effect on regular employment, for instance, corresponds to an accumulated difference of only 0.28 weeks between the two randomly assigned groups. ${ }^{21}$

Turning next to unemployment, Panel H, apart from a short period right after intake, individuals assigned to public services were relatively more likely to be unemployed during the first 46 weeks after enrolment. In week 19, the intention-to-treat effect peaks at 4.3 percentage points and becomes highly statistically significant (p-value: 0.015). This effect, however, dwindles rapidly and it eventually breaks even in week 28. Over the remaining three quarters, the effect is positive first, negative later, but always small and insignificant. Averaging the week-by-week effects across all weeks, we find that individuals receiving public services were 0.7 percentage points more likely to be unemployed on average than their peers in the private program.

Lastly, the effect of being assigned to a public provider on subsidized employment, Panel D,

\footnotetext{
${ }^{20}$ We use weekly data on 3,107 clusters, i.e. 208,169 observations $(3,107 * 67)$.

${ }^{21} 0.42 * 67 / 100=0.28$. Note that this is the effect we obtain after having partialled out the impact of the pre-treatment characteristics summarized in Table 2. Without controls (raw difference in group means), we find that individuals at public providers were employed only 0.03 weeks less ( 0.2 days) on average during the follow-up period of 67 weeks.
} 
is small during the first 26 weeks after randomization, but it gains in magnitude and statistical significance in the longer run. On average across all weeks, assigned-to-public job-seekers were 0.8 percentage points less likely to have a subsidized job than assigned-to-private ones. This translates into a relative decrease in the "number of weeks employed with wage subsidies during follow-up" of approximately 13 percent. Still, the effect is not statistically significant at any conventional level.

Robustness and Sensitivity In this section, we report the results of three robustness and sensitivity tests. First, in an attempt to boost precision, we augment the pooled model specified in equation (2) by a large number of trial site-target group-calender week of intake fixed effects (106 dummies). The results of this sensitivity exercise are presented in Table 5. We report estimates of $\bar{\delta}$ - the average-over-all-weeks effect of being assigned to public instead of private services - obtained both with and without controlling for the aforementioned fixed effects, where the latter correspond to those presented graphically in Figure 6 (dashed lines). It is immediately seen that our results are robust to the inclusion of trial site-target group-calender week of intake fixed effects. It is also seen that the precision gain is negligible.

Table 5: Average-over-all-weeks effect of being assigned to public instead of private employment services estimated with and without trial site-target group-calender week of intake fixed effects

\begin{tabular}{|c|c|c|c|c|c|c|c|c|}
\hline & \multicolumn{2}{|c|}{$\begin{array}{c}\text { Regular } \\
\text { employment }\end{array}$} & \multicolumn{2}{|c|}{$\begin{array}{c}\text { Subsidized } \\
\text { employment }\end{array}$} & \multicolumn{2}{|c|}{$\begin{array}{l}\text { Non-benefit } \\
\text { receipt }\end{array}$} & \multicolumn{2}{|c|}{ Unemployment } \\
\hline & (1) & $(2)$ & $(3)$ & $(4)$ & $(5)$ & (6) & (7) & (8) \\
\hline Assigned public & $\begin{array}{c}-0.42 \\
(1.19)\end{array}$ & $\begin{array}{l}-0.45 \\
(1.18)\end{array}$ & $\begin{array}{l}-0.82 \\
(0.56)\end{array}$ & $\begin{array}{l}-0.75 \\
(0.56)\end{array}$ & $\begin{array}{l}-0.46 \\
(1.17)\end{array}$ & $\begin{array}{c}-0.49 \\
(1.16)\end{array}$ & $\begin{array}{c}0.71 \\
(1.13)\end{array}$ & $\begin{array}{c}0.76 \\
(1.12)\end{array}$ \\
\hline Fixed effects & No & Yes & No & Yes & No & Yes & No & Yes \\
\hline Controls & Yes & Yes & Yes & Yes & Yes & Yes & Yes & Yes \\
\hline
\end{tabular}

Notes: 1st robustness test. The table displays the average-over-all-weeks effect of being assigned to public instead of private employment services measured in percentage points, equation (2). We report estimates obtained both with and without controlling for trial site-target group-calender week of intake fixed effects. Outcome variables are described in Chapter 4. Control variables, which are included in all specifications, are the pre-treatment characteristics summarized in Table 2 (with age entering linearly, not as dummy-coded categorical predictor). Cluster-robust standard errors in parentheses (clustered at the individual level). 3,107 clusters. 208,169 observations.

Significance levels: ${ }^{*} p<0.10,{ }^{* *} p<0.05,{ }^{* * *} p<0.01$

As a second robustness test, we use a more sophisticated model than the pooled linear probability model utilized above to determine whether the overall effect of offering public instead of private services is positive or negative. Specifically, given that we are considering binary dependent variables, we re-estimate the pooled model specified in equation (2) using a logit approach. Results are reported in Table 6, where coefficients have an odds ratio interpretation. Note that an odds ratio close to unity is indicative of no difference in the odds of experiencing an event. To give a reading example, the estimate displayed in column (2) suggests that the odds of individuals assigned to public services to be regularly employed were, on average across all weeks, "only" 0.98 times as large as the odds of individuals assigned to private services (conditional on 
pre-treatment characteristics). The odds ratios presented in Table 6 corrobate our main results (see Figure 6): individuals randomized into public services had, on average across all weeks, marginally smaller odds to be regularly employed, smaller odds to have a subsidized job, slightly smaller odds to be self-sufficient, and higher odds to be unemployed compared with individuals assigned to the private program. All effects are in favor of private providers, but they are small and insignificant (cluster-robust p-values in parentheses).

Table 6: Average-over-all-weeks effect of being assigned to public instead of private employment services estimated using a logit model

\begin{tabular}{|c|c|c|c|c|c|c|c|c|}
\hline & \multicolumn{2}{|c|}{$\begin{array}{c}\text { Regular } \\
\text { employment }\end{array}$} & \multicolumn{2}{|c|}{$\begin{array}{c}\text { Subsidized } \\
\text { employment }\end{array}$} & \multicolumn{2}{|c|}{$\begin{array}{l}\text { Non-benefit } \\
\text { receipt }\end{array}$} & \multicolumn{2}{|c|}{ Unemployment } \\
\hline & $(1)$ & $(2)$ & $(3)$ & (4) & $(5)$ & $(6)$ & $(7)$ & $(8)$ \\
\hline Odds ratio (public/private) & $\begin{array}{c}1.00 \\
{[0.970]}\end{array}$ & $\begin{array}{c}0.98 \\
{[0.711]}\end{array}$ & $\begin{array}{c}0.86 \\
{[0.109]}\end{array}$ & $\begin{array}{c}0.88 \\
{[0.157]}\end{array}$ & $\begin{array}{c}1.00 \\
{[0.990]}\end{array}$ & $\begin{array}{c}0.98 \\
{[0.667]}\end{array}$ & $\begin{array}{c}1.02 \\
{[0.743]}\end{array}$ & $\begin{array}{c}1.04 \\
{[0.519]}\end{array}$ \\
\hline Controls & No & Yes & No & Yes & No & Yes & No & Yes \\
\hline
\end{tabular}

Notes: 2nd robustness test. The table displays the average-over-all-weeks effect of being assigned to public instead of private employment services, equation (2), using a logit model. Coefficients have an odds ratio interpretation. Outcome variables are described in Chapter 4. Control variables are the pre-treatment characteristics summarized in Table 2 (with age entering linearly, not as dummy-coded categorical predictor). Cluster-robust p-values in parentheses (standard errors are clustered at the individual level). 3,107 clusters. 208,169 observations.

Significance levels: ${ }^{*} p<0.10,{ }^{* *} p<0.05,{ }^{* * *} p<0.01$

Thirdly, we consider the effect of being assigned to public services on an alternative outcome variable: the bonus share. We have already introduced this concept in Chapter 3. As a reminder, the bonus share corresponds to the number of big bonus equivalents granted per client (two small bonuses are equivalent to one big bonus). While public job centers did not actually receive bonus payments, we can calculate how many bonuses they would have received if they had been rewarded according to the same bonus scheme as private providers (ex-post). What we do is the following: first, we calculate how many big bonus equivalents each job-seeker generated (hypothetically) over the course of the experiment; let us denote this variable by $B B E$. Second, we regress $B B E$ on Public. The coefficient we obtain captures the difference in the mean number of big bonus equivalents between assigned-to-public and assigned-to-private job-seekers, which corresponds to the difference in bonus shares between the public and the private program. As for our main outcome variables, we find that public and private service providers are equally successful: the bonus shares of both programs are virtually identical (0.494 vis-à-vis 0.498).

Treatment Effect Heterogeneity Figure A2 in the Appendix shows intention-to-treat effects for various subpopulations. We split the sample by target group (younger than 30 versus 30 or older), gender (male versus female), migrant status (Danish versus non-Danish origin), employment experience (individuals with versus individuals without employment experience within the last three years), and trial site (Copenhagen versus Aarhus). The considered outcome variable is unsubsidized contributory employment ("regular employment") in all cases. 
Table 7: The effect of being assigned to public instead of private employment services on big bonus equivalents

\begin{tabular}{lcc}
\hline & \multicolumn{2}{c}{ Big bonus equivalents } \\
\cline { 2 - 3 } & $(1)$ & $(2)$ \\
\hline Assigned public & -0.004 & -0.005 \\
& $(0.020)$ & $(0.020)$ \\
Controls & No & Yes \\
Mean private & 0.498 & 0.498 \\
\hline
\end{tabular}

Notes: 3rd robustness test. The table displays the effect of being assigned to public instead of private employment services. The considered outcome variable is the number of big bonus equivalents granted per enrolled job-seeker. Point estimates correspond to the difference in bonus shares between the public and the private program. Control variables are the pre-treatment characteristics summarized in Table 2 (with age entering linearly, not as dummy-coded categorical predictor). "Mean private" refers to the bonus share of the private program. Robust standard errors in parentheses. 3,107 observations.

Significance levels: ${ }^{*} p<0.10,{ }^{* *} p<0.05,{ }^{* * *} p<0.01$

The findings suggest, first, that there is no substantial heterogeneity in treatment effects along the age dimension. Second, being assigned to a private provider appears to be especially beneficial for men and for individuals with prior employment experience: for these groups, the assigned public effect on regular employment is negative in (almost) all weeks. ${ }^{22}$ Being assigned to a public provider of employment services decreases the employment probability of men, for instance, by 2.7 percentage points (on average across all weeks). ${ }^{23}$ However, this effect is statistically insignificant (p-value: 0.144 ). And thirdly, while we did not find significant performance differentials between private and public service provision for the full sample, the private program clearly outperformed the public one in Aarhus (the second biggest trial site). In Aarhus, the assigned public effect on regular employment is large in magnitude ( -4.5 percentage points on average across all weeks) and statistically significant at the ten percent level (p-value: 0.070). The 4.5 percentage points effect corresponds to relative decrease in employment rates of more than ten percent.

\section{Cost-Analysis}

Methodology The cost-analysis presented in this section quantifies the budgetary burdens associated with public and private provision of employment services. We aim to compare the per capita "price tags" of both programs. Public job centers versus private service providers: Who wins on price? It is important to bear in mind that the analysis is focusing on budgetary expenditures (public spending); we do not account for budgetary revenue effects. Therefore, our estimates do not capture the hypothetical costs of forgone tax revenue due to unemployment or reduced revenue from social contributions.

\footnotetext{
${ }^{22}$ For the group of individuals with prior employment experience, our findings appear to be in line with those of Bennmarker et al. (2013: 77), who find that "the positive effects of switching to a private employment agency are concentrated among individuals with higher-than-average yearly earnings prior to randomization".

${ }^{23}$ Given that the mean employment probability of men (across all weeks) in the private program stands at 41 percent, a 2.7 percentage points effect corresponds to a relative decrease of almost seven percent.
} 
The Costs of the Public Program From a public spending perspective, individuals assigned to public employment services generate three types of costs. The first - and most immediate cost is the cost for human inputs in the caseworking process, i.e. the caseworkers' time. The second is the cost for participation in active labour market programs, such as costs for classroom training and self-chosen education. The third is transfer payments. Transfer payments are due to their purely redistributive nature normally not included in a cost-benefit type of analysis, but they do matter from a public spending perspective.

Regarding the cost for human inputs in the caseworking process, we follow Boll, Jensen, Rosholm, and Svarer (2013) and assume that the first consultative meeting between a job-seeker and his or her caseworker is of one hour duration, whereas all successive follow-up meetings are assumed to take up only half an hour of the caseworker's time. The assumption of diminishing marginal meeting costs is owed to the fact that certain tasks have to be performed only once right at the beginning of the caseworking process: getting to know each other; exchanging documents and general information; assessing the client's needs and expectations; etc. Note further that implicit in our approach is the assumption that caseworkers do not spend time on their cases other than during meetings; or, alternatively, we could assume that the estimated durations already contain these times. To attach a monetary value to the caseworkers' time we use the hourly wage of caseworkers in Denmark, which, according to Boll et al. (2013), amounted to 364 DKK in the year 2012.

As to the cost for participation in active labour market programs, we set the cost per participant-week equal to 1,770 DKK - a cost estimate provided by the National Labour Market Authority (see Boll et al. (2013)). Note, however, that this applies only to counseling programs, classroom training, and self-chosen education. Temporary work experience and subsidized employment, on the other hand, are not associated with direct costs to the public (wage subsidies are transfer payments).

Lastly, regarding transfer payments, we make use of the same weekly benefit rates as Boll et al. (2013). Transfer payments include unemployment benefits, social assistance benefits, wage subsidies, and many more. Table A3 in the Appendix lists the weekly benefit rates used for cost-analysis for all relevant labour market states/DREAM codes.

The Costs of the Private Program For individuals assigned to private providers, the first cost component consists of the direct costs of contracted-out services, i.e. operation subsidy and bonus payments (exclusive of tax), which depend upon the third parties' placement performance; second, the cost for those active labour market programs that are not borne by private contractors themselves (this concerns only self-chosen education; 1,770 DKK per participant-week); and third, as above, transfer payments (Table A3). 
Regarding the direct costs of contracted-out services, we lack data on operation subsidies and bonuses awarded to private contractors in compensation for their services. However, we can use DREAM data (weekly data on the trial participants' labour market status, see Chapter 4) to calculate which subsidies and bonuses should have been granted according to the remuneration scheme contractors were subjected to. We have all the information needed for doing this accurately, with one exception: we could not get access to provider-specific prices for all contractors involved in the experiment. Recall that private providers had to offer a total price per job-seeker per target group per year, see Chapter 3. Depending on actual performance (which we can observe), contractors receive some multiple of their contracted price in forms of operation subsidy and bonus payments. We are able to infer the multiplier from observed performance, but we do not know the contracted price. The only information on contracted prices available to us is the data presented earlier in Figure 3, which shows the distribution of contracted prices by target group for some of the other actors that have been awarded a service contract in the 2010 tendering round. In what follows, we assume that the target group-specific mean prices displayed in Figure 3 are representative for the private providers actually involved in the experiment.

Time Horizons for Cost-Analysis Each cost type is associated with a type-specific time horizon relevant for cost-analysis (the period in which costs are assessed). As discussed above, we differentiate between meeting costs (public only), the cost for participation in active labour market programs (mostly public), direct costs of contracted-out services (private only), and transfer payments (public and private).

Firstly, regarding direct costs of contracted-out services, i.e. operation subsidy and bonus payments, we need to set the length of the relevant observation window equal to 52 weeks (even though the experiment came to an early end in the end of June 2012). This is due to the fact that the contractual assignment period amounted to an entire year (52 weeks); procurement contracts do not contain provisions for shorter actual assignment periods, such as those emanated from the unforeseen changes in the relevant legislation described in Chapter 3.

On first view, one might suppose that the discrepancy between the contractual and the actual assignment period poses a problem to our cost-analysis. Using the contractual instead of the actual assignment period is like masking the fact that the experiment actually did come to an early end. Does this stand to reason? Arguably, yes. First, we have seen earlier that public and private provision of employment services are equally effective regarding subsequent labour market outcomes. It follows immediately that individuals assigned to private services should not have performed differently in our setting than they would have done if the experiment did not come to an early end, i.e. if there were no discrepancy between the contractual and the actual assignment period. This, in turn, implies that operation subsidy and bonus payments calculated 
for the contractual assignment period (masking the fact that the experiment came to an early end) would not have been different if clients assigned to private services had completed a full term - 52 weeks - with private providers. Hence, using the contractual assignment period is legitimate. Second, focusing on the contractual assignment period also scores high from an external validity perspective: in the Danish quasi-market for employment services - contracting out was the default treatment for unemployed academics from 2007 to 2011 - services were normally contracted out for 52 weeks. The shorter actual assignment period in our setting resulted from an exogenous shock not common to regular quasi-markets. And third, we have, in fact, no choice but to use the contractual assignment period: as far as operation subsidy and bonus payments are concerned, we would not be able to do cost calculations for the actual one.

Secondly, regarding the cost for participation in active labour market programs, we use pursuant to the rationale expressed above - the contractual assignment period as time frame for cost-analysis. That is to say the cost for participation in active labour market programs are assessed for a time horizon of 52 weeks, measured from the individual date of intake.

Thirdly, for meeting costs, the relevant observation window spans from the start of the experiment up until the assignment period's end in the end of June 2012. ${ }^{24}$ It might seem incoherent to use the actual assignment period for meeting costs (public only) after having used the contractual one for the cost types discussed earlier. However, since we cannot observe meetings taking place after the assignment period's end, we are, in fact, forced to do so. Note that this puts public service providers at an advantageous position, since meeting costs for the contractual assignment period would be higher. However, the bias should be small. First, most meetings are taking place right after intake, when a large fraction of clients is still searching for employment. ${ }^{25}$ And second, meeting costs constitute only a small portion of total costs.

Lastly, regarding transfer payments, we assess all benefits disbursed to trial participants from the start of the experiment up until 67 weeks after randomization; this is the last week during which we still observe all participants. Since transfer payments is a cost type that is relevant for treated and controls in the same manner, the choice of the time horizon used for cost-analysis is rather uncritical, as long as it is the same for both groups. We opted for an observation window as large as possible, given the data at hand.

Results The results of our cost-analysis are displayed in Table 8. It is immediately seen that the two competing service delivery systems are equally costly from a public spending perspective. A graphical illustration of this finding is provided in Figure 7, which shows density estimates of the costs per trial participant by assignment status together with group-specific means.

\footnotetext{
${ }^{24}$ Recall that, in case of continued unemployment, both groups received public services from July 2012 onwards (Figure 2).

${ }^{25}$ At the assignment period's end, only about a third of all assigned-to-public individuals was still registered as
} 
Figure 7: Kernel density estimates of costs per trial participant by assignment status (DKK)

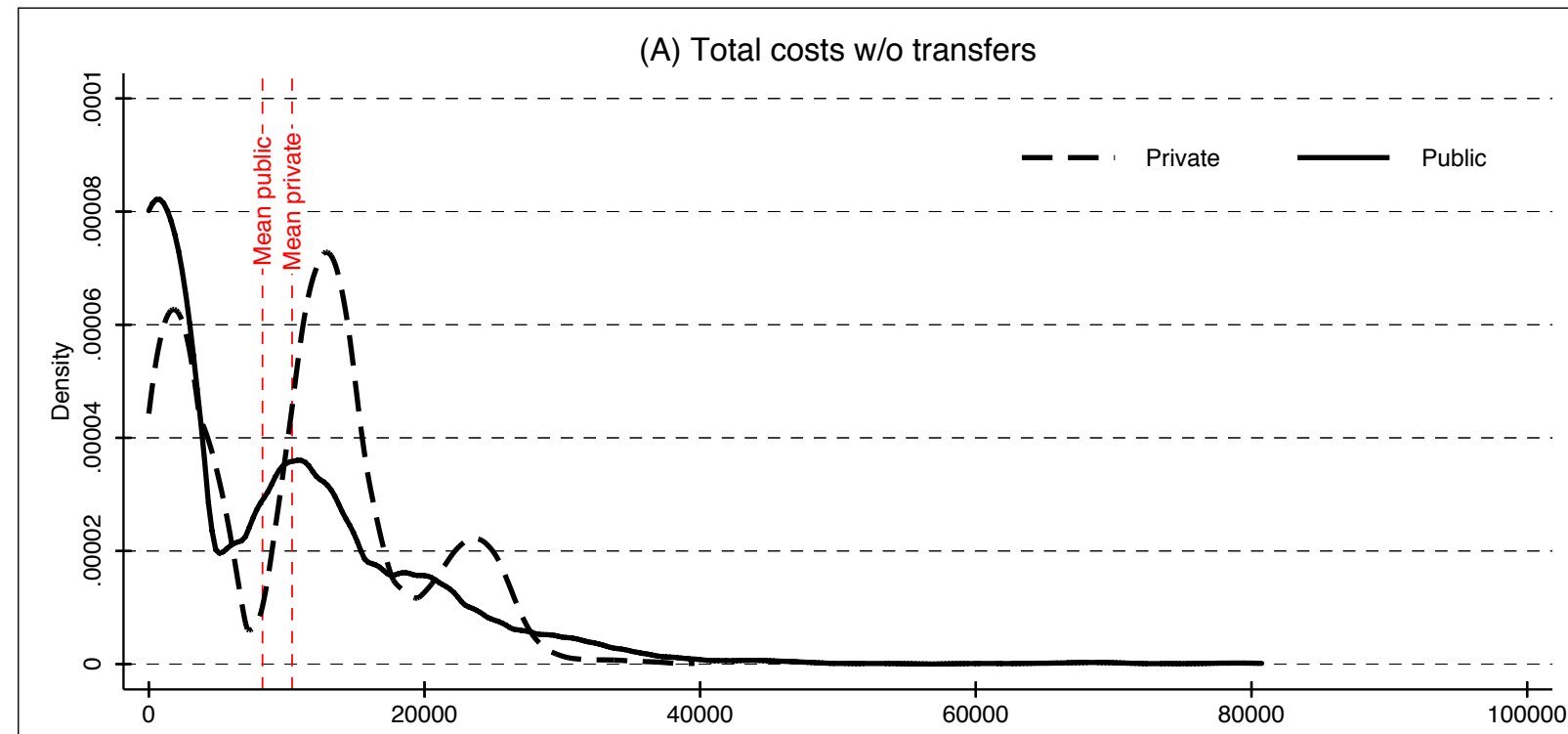

(B) Transfer payments
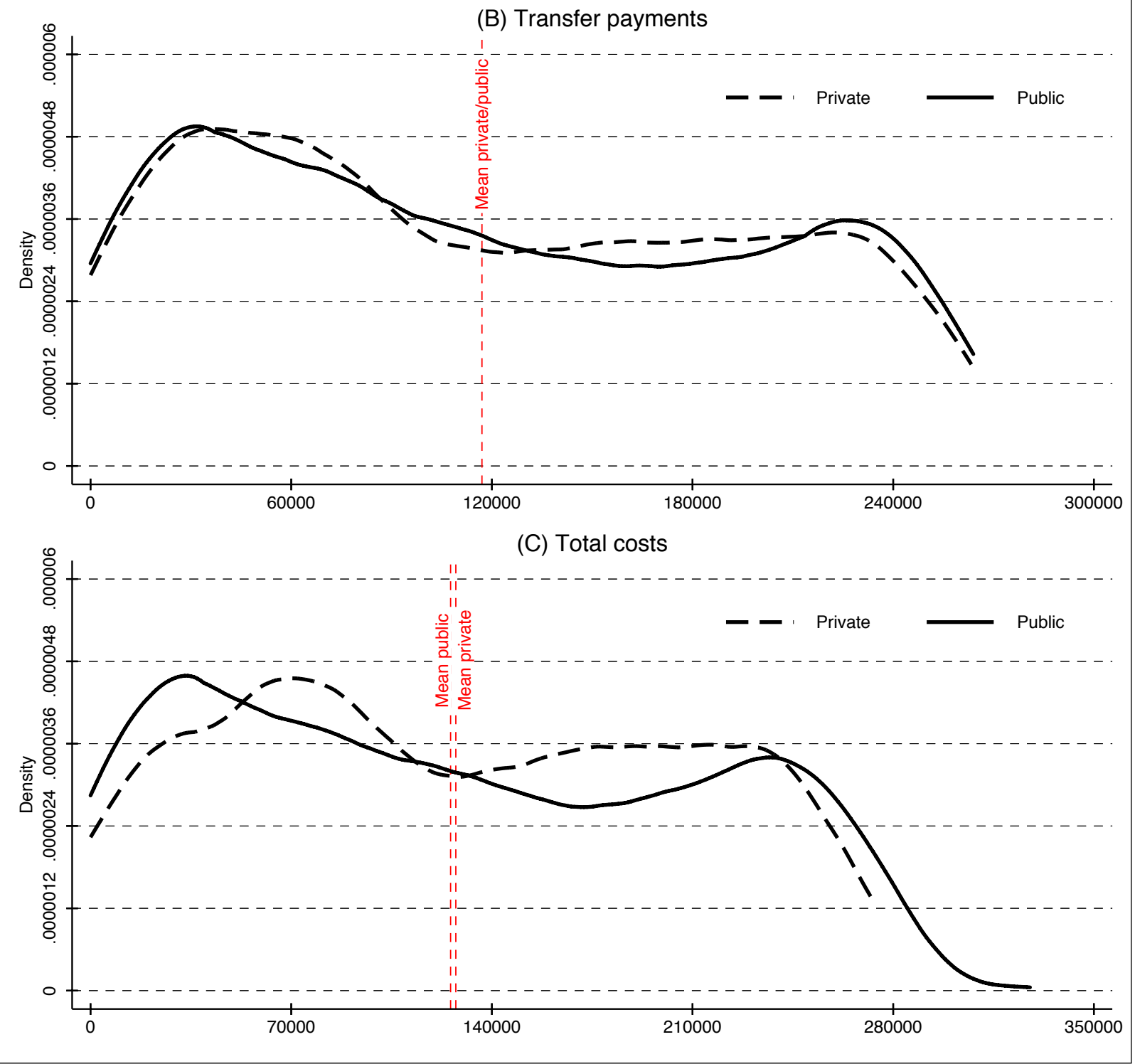

Notes: Costs are in Danish Kroner (DKK) and expressed in per capita terms. Density estimates are based on Epanechnikov kernels with optimal bandwidths. Group means are inferred from Table 8. 
Table 8: Costs per trial participant by assignment status (DKK)

\begin{tabular}{|c|c|c|c|c|c|c|}
\hline & \multicolumn{2}{|c|}{ Total costs w/o transfers } & \multicolumn{2}{|c|}{ Transfer payments } & \multicolumn{2}{|c|}{ Total costs } \\
\hline & (1) & $(2)$ & $(3)$ & (4) & (5) & (6) \\
\hline Assigned public & $\begin{array}{c}-2,144^{* * *} \\
(324)\end{array}$ & $\begin{array}{c}-2,083^{* * *} \\
(320)\end{array}$ & $\begin{array}{c}306 \\
(2,829)\end{array}$ & $\begin{array}{c}1,236 \\
(2,720)\end{array}$ & $\begin{array}{l}-1,838 \\
(2,941)\end{array}$ & $\begin{array}{c}-847 \\
(2,832)\end{array}$ \\
\hline Controls & No & Yes & No & Yes & No & Yes \\
\hline Mean private & 10,392 & 10,392 & 117,038 & 117,038 & 127,430 & 127,430 \\
\hline
\end{tabular}

Notes: The table displays the results of our cost-analysis. Costs are in Danish Kroner (DKK) and expressed in per capita terms. Control variables are the pre-treatment characteristics summarized in Table 2 (with age entering linearly, not as dummy-coded categorical predictor). "Mean private" refers to the mean of the corresponding outcome among individuals assigned to private services. Robust standard errors in parentheses. 3,107 observations.

Significance levels: ${ }^{*} p<0.10,{ }^{* *} p<0.05,{ }^{* * *} p<0.01$

Column (1) shows that mean total costs without transfer payments are 10,392 DKK for individuals assigned to private services ("Mean private"). Mean costs for individuals assigned to public services are smaller and the difference of 2,144 DKK is statistically significant at the one percent level ("Assigned public"). This result is robust to the inclusion of additional controls, column (2). Regarding transfer payments, column (3) and column (4), both treated and controls received on average approximately 117,000 DKK in social benefits during follow-up. The difference in mean benefit expenditures is very small and insignificant. Turning next to column (5) and column (6), mean total costs of the private program exceed those of the public one by 1,838 DKK. Given the equality of mean transfer payments across groups, this difference is almost entirely driven by the difference in total costs without transfers. Including additional controls results in an assigned public effect on total costs of about -850 DKK. This effect is small in magnitude and not statistically significant at conventional levels (p-value: 0.765).

\section{Conclusion}

Reporting from a large-scaled randomized field experiment we assessed empirically the case for contracting out employment services for unemployed individuals holding a university degree. Since our paper is the first with explicit focus on highly educated job-seekers, we filled an important research gap. All previous trials assess the relative merits of public and private service provision for economically disadvantaged populations with poor baseline employment prospects (hard-to-place individuals). By combining the gold standard methodology in empirical research (random assignment) with register data of exceptional high quality, our study yields results with a high degree of internal validity.

Our findings suggest that public and private provision of employment services are equally effective regarding subsequent labour market outcomes. There are, however, some indications that the relative performance of public and private service provision depends on context: while 
we did not find any substantial performance differentials for the full sample, men and individuals with prior employment experience tend to do better in the private track. However, this evidence is tentative at best. We have also found that the private program clearly outperformed the public one in Aarhus (the second biggest trial site), whereas the public one tended to be slightly more successful in Copenhagen. In sum, these two effects cancel out and overall performance differentials are very small and insignificant. Regarding costs, we have quantified the budgetary burdens associated with public and private service provision. Our cost-analysis indicates that the per capita price tags of both programs are comparable, i.e. the programs are by and large equally costly. When it comes to working methods, there exist some notable differences: private providers deliver more intense, employment-oriented, and earlier services.

The main policy implication of our analysis is that there is no one-size-fits-all approach to delivering employment services for the highly educated. While private and public service providers are on a par with each other overall, this does not generally mean that ownership does not matter. In particular, the relative merits of private and public service provision appear to depend both on client characteristics (gender, experience) and on local labour market conditions (Copenhagen versus Aarhus). In short, diversified characteristics and conditions may call for tailor-made solutions. 


\section{References}

Arbejdsmarkedsstyrelsen (2010). Udbud af Kontakt- og Aktiveringsforl øb for Ledige med Lange Videregående Uddannelser 2010: Kravspecifikation.

Behaghel L., Crépon B., and Gurgand M. (2014). Private and Public Provision of Counseling to Job Seekers: Evidence from a Large Controlled Experiment. American Economic Journal: Applied Economics, 6(4): 142-74.

Bennmarker H., Grönqvist E., and Öckert B. (2013). Effects of Contracting out Employment Services: Evidence from a Randomized Experiment. Journal of Public Economics, 98: 68-84.

Bernhard S. and Wolff J. (2008). Contracting out Placement Services in Germany: Is Assignment to Private Providers Effective for Needy Job-seekers? Institute for Employment Research (IAB), Discussion Paper 5/2008.

Boll J., Jensen S., Rosholm M., and Svarer M. (2013). Evaluering: På Rette Vej - i Job. Arbejdsmarkedsstyrelsen, Slutrapport.

Bredgaard T., Larsen F., and Møller L. (2005). Inddragelsen af Andre Aktører i Beskæftigelsespolitikken. Tidsskrift for Arbejdsliv, 7(2): 9-27.

Carcagno G., Cecil R., and Ohls J. (1982). Using Private Employment Agencies to Place Public Assistance Clients in Jobs. Journal of Human Resources, 17(1): 132-143.

Card D., Kluve J., and Weber A. (2010). Active Labour Market Policy Evaluations: A MetaAnalysis. The Economic Journal, 120(548): 452-477.

Cockx B. and Baert S. (2015). Contracting Out Mandatory Counselling and Training for LongTerm Unemployed. Private For-Profit or Non-Profit, or Keep it Public? Mimeo.

Finn D. (2011). Sub-contracting in Public Employment Services: Review of Research Findings and Literature on Recent Trends and Business Models. The European Commission Mutual Learning Programme for Public Employment Services, DG Employment, Social Affairs and Inclusion.

Gratadour C. and Le Barbanchon T. (2009). Les Expérimentations d'Accompagnement Renforcé de l'Unédic et de l'ANPE: Contenu des Accompagnements et Opinion des Bénéficiaires. Premières Synthèses, 41(2): 127-134.

Heckman J., LaLonde R., and Smith J. (1999). The Economics and Econometrics of Active Labor Market Programs. Handbook of Labor Economics, 3: 1865-2097. 
Krug G. and Stephan G. (2013). Is the Contracting-Out of Intensive Placement Services More Effective than Provision by the PES? Evidence from a Randomized Field Experiment. Institute for the Study of Labor (IZA), Discussion Paper 7403.

Laun L. and Thoursie P. (2014). Does Privatisation of Vocational Rehabilitation Improve Labour Market Opportunities? Evidence from a Field Experiment in Sweden. Journal of Health Economics, 34: 59-72.

Rambøll (2012). Evaluering af Kontrolleret Fors $\emptyset$ g med LVU-indsatsen. Arbejdsmarkedsstyrelsen, Rapport.

Rigsrevision (2013). Beretning til Statsrevisorerne om Effekten og Kvaliteten af Andre Aktørers Beskæftigelsesindsats.

Rosenbaum P. and Rubin D. (1983). The Central Role of the Propensity Score in Observational Studies for Causal Effects. Biometrika, 70(1): 41-55.

Skipper L. and Sørensen K. (2013). Effekten af Andre Aktørers Beskæftigelsesindsats: Effektundersøgelse af Indsatsen for Ledige Henvist til Andre Aktører Under Serviceudbuddet 2009. Det Nationale Institut for Kommuners og Regioners Analyse og Forskning (KORA), Projekt 10329.

Thygesen L., Daasnes C., Thaulow I., and Brønnum-Hansen H. (2011). Introduction to Danish (Nationwide) Registers on Health and Social Issues: Structure, Access, Legislation, and Archiving. Scandinavian Journal of Public Health, 39(7): 12-16.

Winterhager H. (2006). Private Job Placement Services - A Microeconometric Evaluation for Germany. Centre for European and Economic Research (ZEW), Discussion Paper 06-026.

Zweifel P. and Zaborowski C. (1996). Employment Service: Public or Private? Public Choice, 89(1-2): 131-162. 
Appendix A 


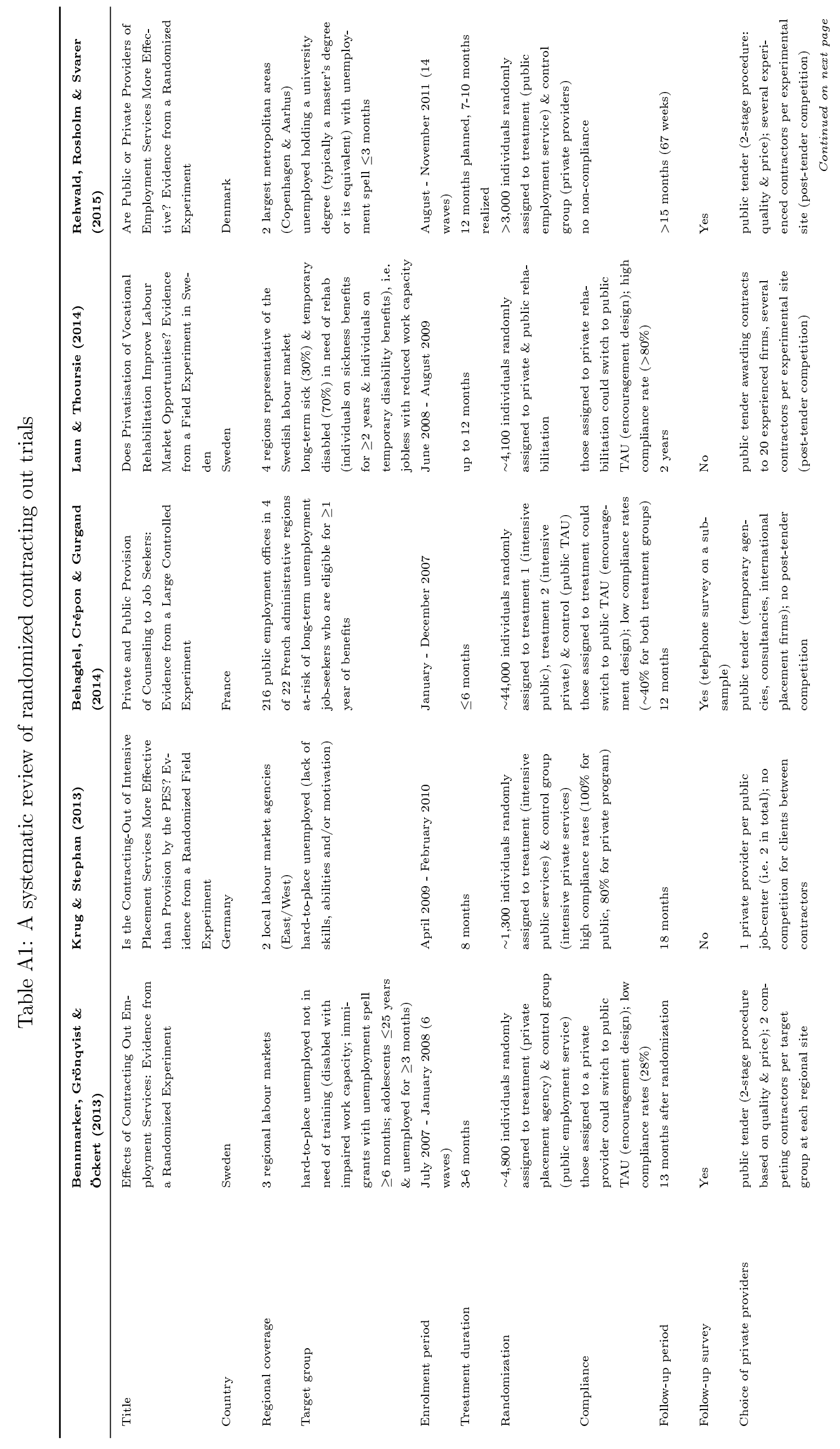




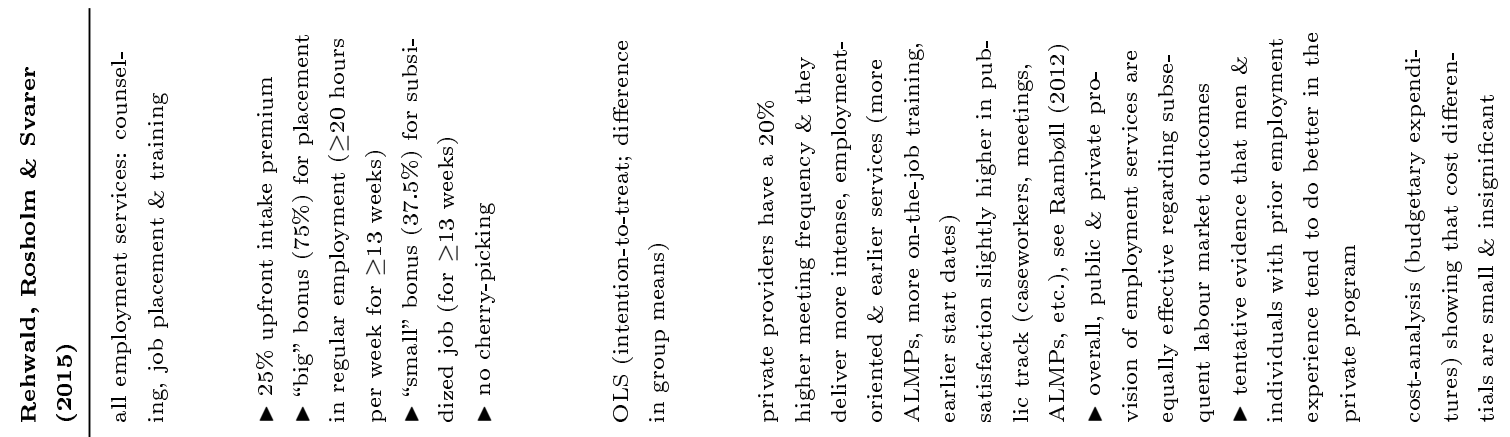

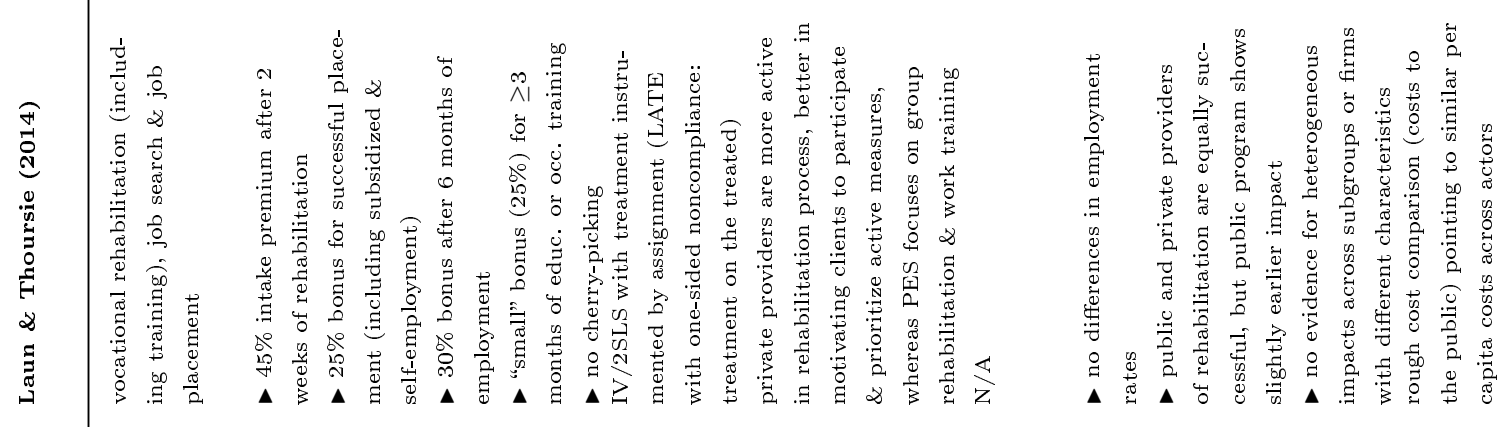

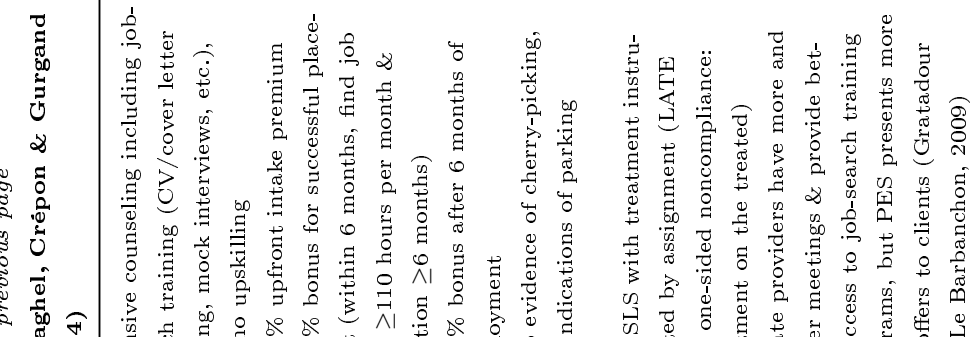

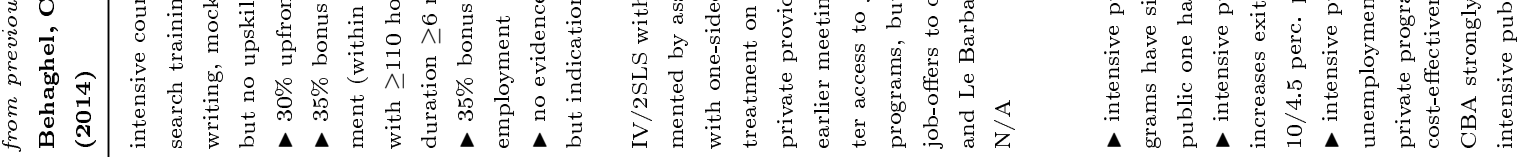
हैं

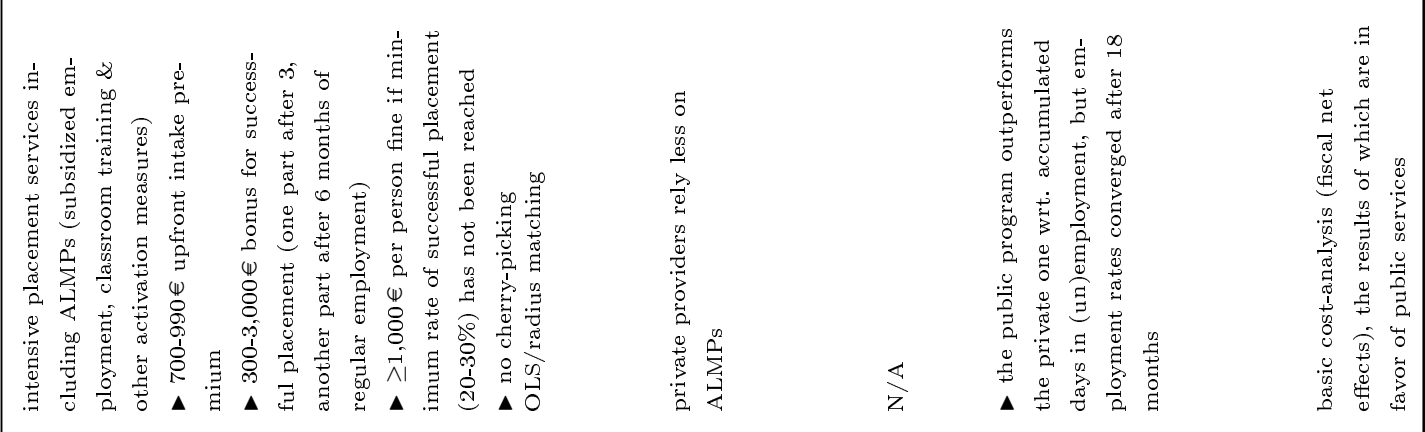
In MUM WM

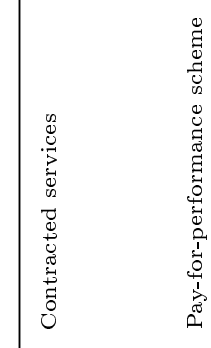<smiles>CCCCC</smiles> 
Table A2: DREAM codes associated with outcome variables

\begin{tabular}{ll}
\hline Variable & DREAM codes \\
\hline Regular employment & 500 \\
Subsidized employment & $135,136,215,216,735,736,745,746,755,756$, \\
& $765,766,895,896$ \\
Non-benefit receipt & $500,997,999$, and all missing entries \\
Unemployment & $111,112,124,125,130,131,132,133,134,135$, \\
& $136,137,138,211,212,213,214,215,216,217$, \\
& $218,231,232,299,730,731,732,733,734,735$, \\
& $736,737,738$ \\
\hline
\end{tabular}

Notes: The table lists the DREAM codes associated with each of our four main outcome variables. The code listing refers to DREAM Version 28 (March 2012). Code 500 stems from the electronic income register. A missing DREAM code implies that an individual received no transfer payments in a given week. Missing entries are therefore associated with the outcome variable non-benefit receipt. 
Figure A1: Inflow into the experiment (on the left) and stock of participants (on the right) between mid August and mid November 2011 by (A) treatment status, (B) target group, (C) regional trial site, and (D) other actor

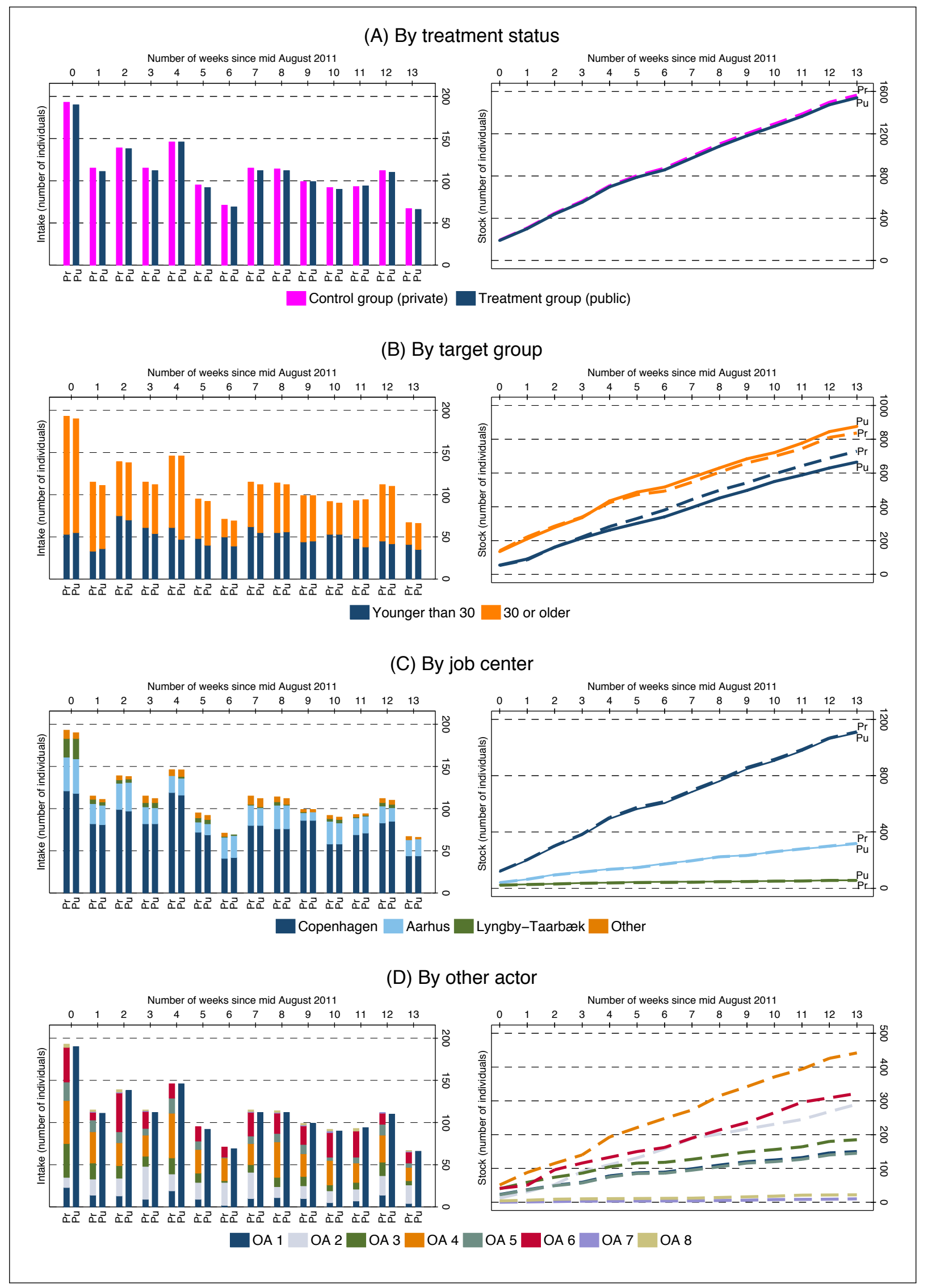

Notes: Week 0 corresponds to calendar week 33 (15.08-21.08.2011) and week 13 to week 46 (14.11.-20.11.2011). Dashed lines refer to the control group (private), solid lines to the treatment group (public). Panel (C): The stock for "Other" is omitted. Panel (D): Other actor 8 (OA 8 ) is a residual category. 
Figure A2: The effect of offering public instead of private services on regular employment for various subpopulations

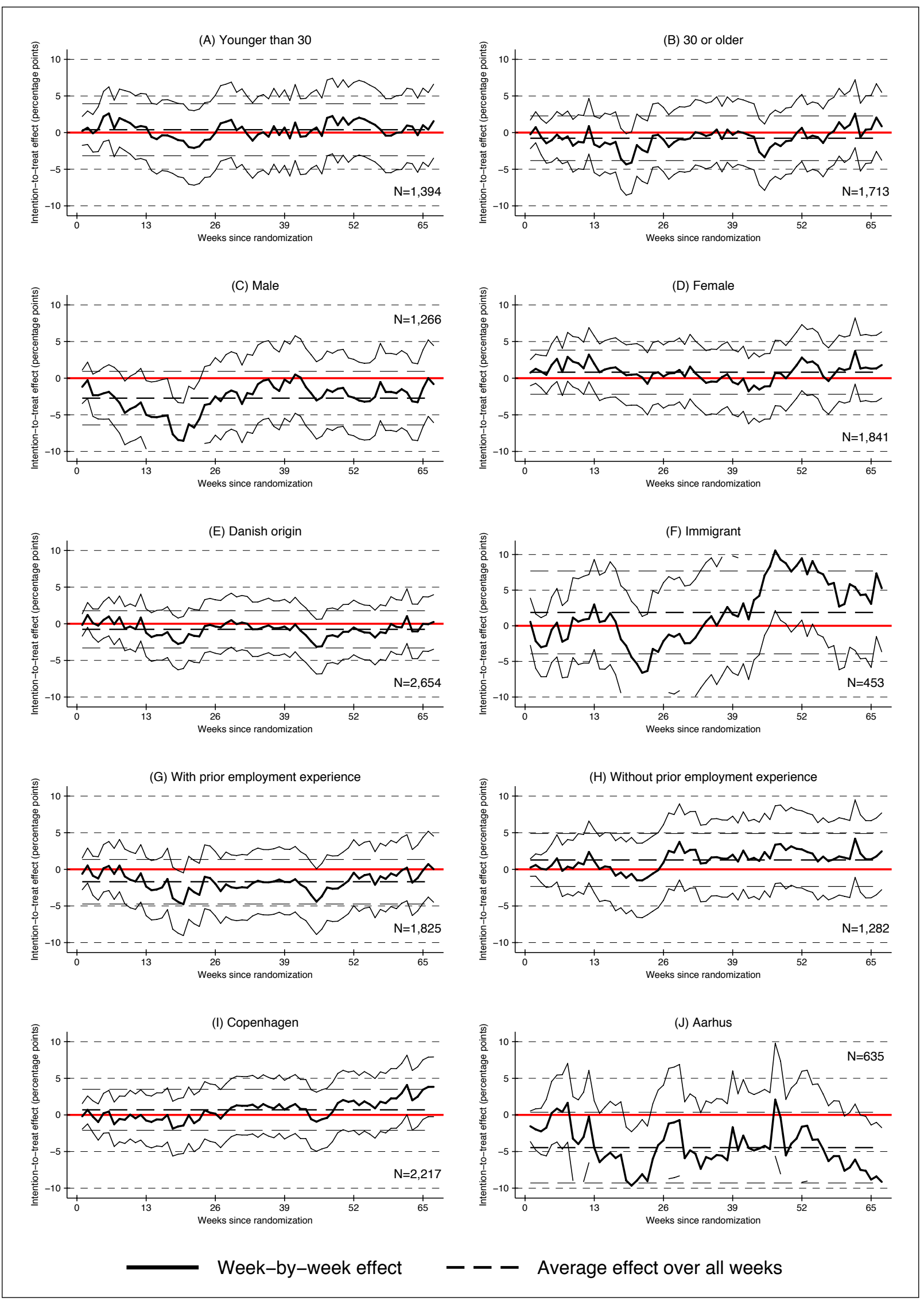

Notes: The figure displays the effect of being assigned to public instead of private employment services measured in percentage points together with a 95 percent confidence interval; see equation (1) for the week-by-week effect, and equation (2) for the average effect over all weeks. The considered outcome variable is regular employment in all cases. Confidence bounds are censored at \pm ten percentage points for illustrational purposes. 
Table A3: Transfer payments

\begin{tabular}{|c|c|c|c|}
\hline Labour market status & DREAM codes & $\begin{array}{l}\text { Weekly benefit rate } \\
\text { (DKK) }\end{array}$ & $\begin{array}{c}\% \text { of all } \\
\text { observations }\end{array}$ \\
\hline \multicolumn{3}{|l|}{ Panel A: Non-benefit receipt (NBR) } & $(46.3)$ \\
\hline NBR due to regular employment & 500 & 0 & 37.7 \\
\hline NBR due to emigration & 997 & 0 & 2.9 \\
\hline NBR due to death & 999 & 0 & $<0.1$ \\
\hline NBR for other reasons & all missing entries & 0 & 5.8 \\
\hline \multicolumn{3}{|c|}{ Panel B: Unemployment benefits while being passive } & $(29.4)$ \\
\hline Full unemployment & 111 & 3,739 & 24.0 \\
\hline Unemployment ( $\geq 50 \%$ of week) & 112 & 2,617 & 3.4 \\
\hline Unemployment $(<50 \%$ of week $)$ & 113 & 1,122 & 2.1 \\
\hline \multicolumn{3}{|c|}{ Panel C: Unemployment benefits for individuals participating in ALMPS } & $(15.9)$ \\
\hline Job counseling & 212,213 & 3,739 & 3.7 \\
\hline Classroom training & 214 & 3,739 & 0.5 \\
\hline Self-chosen education & 231,232 & 3,739 & 2.6 \\
\hline Temporary work experience (priv.) & 217 & 3,739 & 1.7 \\
\hline Temporary work experience (publ.) & 218 & 3,739 & 0.8 \\
\hline Subsidized employment (priv.) & 215 & 2,444 & 1.9 \\
\hline Subsidized employment (publ.) & 216 & 2,180 & 4.7 \\
\hline \multicolumn{3}{|c|}{ Panel D: Social assistance benefits while being passive } & $(0.3)$ \\
\hline Social assistance benefits (passive) & 130,730 & 3,433 & 0.3 \\
\hline \multicolumn{3}{|c|}{ Panel E: Social assistance benefits for individuals participating in ALMPS } & $(0.1)$ \\
\hline Job counseling & $132,133,733$ & 3,433 & 0.1 \\
\hline Classroom training & 134 & 3,433 & $<0.1$ \\
\hline Temporary work experience (priv.) & 137 & 3,433 & $<0.1$ \\
\hline Temporary work experience (publ.) & 138 & 3,433 & $<0.1$ \\
\hline Subsidized employment (priv.) & 135,735 & 2,444 & $<0.1$ \\
\hline Subsidized employment (publ.) & 136,736 & 2,180 & $<0.1$ \\
\hline Other & 139 & 3,433 & $<0.1$ \\
\hline \multicolumn{3}{|c|}{ Panel F: Maternity leave \& sickness benefits } & $(4.8)$ \\
\hline Maternity leave benefits & 881 & 3,940 & 3.0 \\
\hline Sickness benefits & $\begin{array}{c}890,892,893 \\
896-899\end{array}$ & 3,940 & 1.8 \\
\hline \multicolumn{3}{|c|}{ Panel G: Holiday allowances for employed \& unemployed individuals } & $(0.9)$ \\
\hline Full holiday allowance & 121,124 & 3,739 & 0.3 \\
\hline Holiday allowance ( $\geq 50 \%$ of week) & 122,125 & 2,617 & 0.2 \\
\hline Holiday allowance $(<50 \%$ of week $)$ & 123,126 & 1,122 & 0.4 \\
\hline \multicolumn{3}{|l|}{ Panel H: Pensions } & $(0.1)$ \\
\hline Post-employment wage & 621 & 3,739 & 0.1 \\
\hline Early retirement pension & 783 & 3,629 & $<0.1$ \\
\hline Old-age pension & 998 & 2,379 & $<0.1$ \\
\hline \multicolumn{3}{|l|}{ Panel I: Other } & $(2.1)$ \\
\hline Adult apprenticeships & 521 & 1,110 & $<0.1$ \\
\hline Rotational temps & 522 & 3,745 & $<0.1$ \\
\hline Education with education grants & 651 & 1,307 & 1.3 \\
\hline Education w/o education grants & 652 & 0 & 0.8 \\
\hline Extra-occupational education & 661 & 3,739 & $<0.1$ \\
\hline Pre-flexjob benefits & 740,744 & 3,585 & $<0.1$ \\
\hline Vocational rehabilitation & 768 & 3,433 & $<0.1$ \\
\hline
\end{tabular}

Notes: The table displays weekly benefit rates for all labour market states/DREAM codes observed within the relevant observation window (from the start of the experiment up until 67 weeks after randomization). Transfer payments for labour market states/DREAM codes not observed within this observation window are not listed. The code listing refers to DREAM Version 28 (March 2012). We use the same weekly benefit rates as Boll et al. (2013: 45), with the following exceptions. For DREAM codes 137 and 138, we impute a value of 3,433 DKK (instead of 2,012 DKK). For DREAM codes 217 and 218, we impute a value of 3,739 DKK (instead of 2,180 DKK). Benefit rates for DREAM codes $139,522,621$, and 661 are not listed in Boll et al. (2013). For code 139, we use the regular social assistance benefit rate $(3,433 \mathrm{DKK})$. For codes 621 and 661 , we use the regular unemployment benefit rate $(3,739 \mathrm{DKK})$. For code 522 , we impute a value of 3,745 DKK (assuming that rotational temps work 20 hours a week and receive the mean hourly wage subsidy - public (176.20 DKK) versus private (198.34 DKK) - of 187.27 DKK). The table's rightmost column displays the (percentage) frequency distribution of labour market states/DREAM codes within the relevant observation window. 208,169 observations. 